\title{
Mitogen-activated protein kinase cascades in Vitis vinifera
}

\author{
Birsen Çakır $^{1 *}$ and Ozan Kıllı̧kaya ${ }^{2}$ \\ ${ }^{1}$ Department of Horticulture, Faculty of Agriculture, Ege University, Izmir, Turkey, ${ }^{2}$ Department of Pharmacetical \\ Biotechnology, Faculty of Pharmacy, Cumhuriyet University, Sivas, Turkey
}

Protein phosphorylation is one of the most important mechanisms to control cellular functions in response to external and endogenous signals. Mitogen-activated protein kinases (MAPK) are universal signaling molecules in eukaryotes that mediate the intracellular transmission of extracellular signals resulting in the induction of appropriate cellular responses. MAPK cascades are composed of four protein kinase modules: MAPKKK kinases (MAPKKKKs), MAPKK kinases (MAPKKKs), MAPK kinases (MAPKKs), and MAPKs. In plants, MAPKs are activated in response to abiotic stresses, wounding, and hormones, and during plant pathogen interactions and cell division. In this report, we performed a complete inventory of MAPK cascades genes in Vitis vinifera, the whole

Edited by:

Joanna Marie-France Cross, Inönü University, Turkey

Reviewed by:

Matthew R. Willmann, University of Pennsylvania, USA

Pao-Yang Chen,

Academia Sinica, Taiwan Samia Daldoul,

Center of Biotechnology of Borj Cedria, Tunisia

*Correspondence: Birsen Çakır. Department of Horticulture, Faculty of Agriculture, Ege University, Bornova/lzmir 35100, Turkey birsencakir@hotmail.com

Specialty section: This article was submitted to Plant Genetics and Genomics, a section of the journal Frontiers in Plant Science

Received: 08 February 2015 Accepted: 07 July 2015 Published: 22 July 2015

Citation: Çakır B and Kıllçkaya O (2015) Mitogen-activated protein kinase

cascades in Vitis vinifera. Front. Plant Sci. 6:556. doi: 10.3389/fpls.2015.00556 genome of which has been sequenced. By comparison with MAPK, MAPK kinases, MAPK kinase kinases and MAPK kinase kinase kinase kinase members of Arabidopsis thaliana, we revealed the existence of 14 MAPKs, 5 MAPKKs, 62 MAPKKKs, and 7 MAPKKKKs in Vitis vinifera. We identified orthologs of $V$. vinifera putative MAPKs in different species, and ESTs corresponding to members of MAPK cascades in various tissues. This work represents the first complete inventory of MAPK cascades in $V$. vinifera and could help elucidate the biological and physiological functions of these proteins in $V$. vinifera.

\section{Keywords: MAP kinase, Vitis vinifera, signal transduction, protein phosphorylation}

\section{Introduction}

Mitogen-activated protein kinase (MAPK) cascades are higly conserved modules of signal transduction in eucaryotes including yeast, animals, and plants. MAPK cascades play an important role in protein phosphorylation of signal transduction events (Rodriguez et al., 2010). MAPK cascades typically consist of three protein kinases, MAPK, MAPK kinase (MAPKK), and MAPK kinase kinase (MAPKKK), but sometimes include MAP3K kinase (MAP4K) that phosphorylate the corresponding downstream substrates (Jonak et al., 2002; Champion et al., 2004).

MAPK is activated via phophorylation of conserved threonine $(\mathrm{T})$ and tyrosine $(\mathrm{Y})$ residues in the catalytic subdomain by its specific MAPKK, which is in turn activated by phophorylation of two serine/threonine residues in a conserved S/T-X33-5-S/T motif by an upstream MAPKKK (Stulemeijer et al., 2007; Zaïdi et al., 2010; Huang et al., 2011). Upon activation, the MAPK could be translocated into the nucleus or cytoplasm to trigger the cellular responses through phosphorylation of downstream transcription factors or components of transcription machinery while some MAP kinases, like ERK3, are constitutively present in the nucleus and may function

Abbreviations: MAPK, mitogen-activated protein kinase; ORF, open reading frame. 
in the nucleus (Lee et al., 2004; Pedley and Martin, 2005; Fiil et al., 2009; Nadarajah and Sidek, 2010). MAPKKK is usually activated by a $\mathrm{G}$ protein, but sometimes activation is mediated via an upstream MAP4K (Champion et al., 2004).

MAPK proteins contain 11 evolutionary conserved kinase domains that may be involved in substrate specifity or proteinprotein interaction (Nadarajah and Sidek, 2010). MAPK cascade proteins have TEY or TDY phophorylation motifs in the region between kinase domains VII and VIII (Group et al., 2002), which provides a protein-binding domain for the activation of MAPKs (Rohila and Yang, 2007).

In plants, MAPKs are involved in cellular responses to hormones, plant growth and development, regulation of the cell cycle, and responses to biotic and abiotic stresses (Jonak et al., 1993; Wilson et al., 1997; Zhang and Klessig, 1997; Bögre et al., 1999; Nishihama et al., 2001; Bergmann et al., 2004; Lukowitz et al., 2004; Katou et al., 2005; Meng et al., 2012).

A variety of genes encoding MAPKs have been cloned from Arabidopsis, rice, tobacco and barley, and oat (Huttly and Phillips, 1995; Knetsch et al., 1996; Mizoguchi et al., 1998; Nadarajah and Sidek, 2010; Zaïdi et al., 2010; Sun et al., 2014). The Arabidopsis genome contains 20 MAPK genes (Group et al., 2002; Jonak et al., 2002). MAPK genes such as AtMPK4 and AtMPK6, have been identified in Arabidopsis (Ichimura et al., 1998, 2000; Nadarajah and Sidek, 2010). It has been reported that MAPK genes are involved in biotic and abiotic stress responses (Mizoguchi et al., 1996; Ichimura et al., 2000; Asai et al., 2002; Nadarajah and Sidek, 2010). For example, OsMAPK3, OsMAPK6, and the MAPK kinase OsMKK4 are induced by a chitin elicitor in rice and the activated form of OsMKK4 induces cell death (Kishi-Kaboshi et al., 2010). Similarly, NtWIPK, OsMPK5, and AtMPK3 were activated by pathogens and abiotic stresses (Zhang and Klessig, 2001; Hamel et al., 2006; Rohila and Yang, 2007). AtMPK4 and AtMPK6 are activated by osmotic stress, low humidity, low temperature, and wounding (Ichimura et al., 2000; Teige et al., 2004). AtMPK3 and AtMPK6 are also regulated by biotic elicitors via AtMKK $4 / 5$ and AtMPK4 is a negative regulator of defense response (Asai et al., 2002). In addition, AtMPK3 and AtMPK6 are involved in the embryo, anther and inflorescence development and stomatal distribution on the leaf surface (Bergmann et al., 2004; Gray and Hetherington, 2004; Bush and Krysan, 2007).

MKKs are activated by the phosphorylation on conserved serine and threonine residues in the S/T-X3-5-S/T motif and characterized by a putative MAPK-docking domain K/R-K/RK/R-X1-6-L-X-L/V/S, and a kinase domain (Group et al., 2002). To date, many MAPKKs have been identified from several plant species. All the identified MAPKK genes from Arabidopsis, rice and poplar contain 11 catalytic subdomains (Ichimura et al., 2002; Rao et al., 2010; Wang et al., 2014c). In Arabidopsis, MKK1 was activated by wounding and abiotic stress (Matsuoka et al., 2002). Alfalfa SIMKK mediates both salt and elicitor-induced signals (Kiegerl et al., 2000; Cardinale et al., 2002). NtMEK2 activates SIPK and WIPK resulting in cell death (Yang et al., 2001).

MAPKKKs form the largest class of MAPK cascade enzymes with 80 members classified into three subfamilies, MEKK,
Raf, and ZIK containing 21, 11, and 48 genes, respectively in Arabidopsis (Jonak et al., 2002). Plant MAPKKKs are characterized by different primary structures of their kinase domains, but are conserved within a single group (Champion et al., 2004). The MEKK subfamily comprises a conserved kinase domain of G(T/S)Px(W/Y/F)MAPEV (Jonak et al., 2002). The ZIK subfamily contains GTPEFMAPE $(\mathrm{L} / \mathrm{V}) \mathrm{Y}$ while the Raf subfamily has GTxx(W/Y)MAPE (Jonak et al., 2002). All the MAPKKK proteins have a kinase domain, and most of them have a serine/threonine protein kinase active site (Wang et al., 2015). In the RAF subfamily, most of the proteins have a long $\mathrm{N}$-terminal regulatory domain and C-terminal kinase domain. By contrast, majority of the members in the ZIK subfamily have an $\mathrm{N}$-terminal kinase domain (Wang et al., 2015). However, the MEKK subfamily has a less conserved protein structure with a kinase domain located either at the C- or Nterminal or in the central part of the protein (Wang et al., 2015). Homologs of MAPKKKs have been identified in plant species such as alfalfa, Arabidopsis, tobacco (Kovtun et al., 2000; Nishihama et al., 2001; Lukowitz et al., 2004; Nakagami et al., 2004). The MEKK subfamily contains NPK1, NbMAPKKKa, NbMAPKKK $\gamma$, NbMAPKKK $\varepsilon$ in tobacco (Jin et al., 2002; del Pozo et al., 2004; Liu et al., 2004; Melech-Bonfil and Sessa, 2010), MEKK1 in Arabidopsis (Asai et al., 2002), and SIMAPKKK $\alpha$ and SIMAPKKKE in tomato (Oh et al., 2010; Sun et al., 2014). The second subfamily, Raf, includes Arabidopsis CTR1/raf1 (Kieber et al., 1993), EDR/Raf2 (Frye et al., 2001), and DSM1 in rice (Ning et al., 2010). In Arabidopsis, MEKK1 regulates defense responses against different pathogens including bacteria and fungi (Asai et al., 2002; Qiu et al., 2008; Galletti et al., 2011). In addition, AtEDR1, a Raf-like MAPKKK, regulates SA-inducible defense responses (Frye et al., 2001). The ZIK subfamily which contains 10 and 9 members in Arabidopsis and rice, respectively, are able to regulate flowering time and circadian rhythms (Wang et al., 2008; Kumar et al., 2011).

A putative phosphorylation domain $\mathrm{T} / \mathrm{Sx}_{5} \mathrm{~T} / \mathrm{S}$ is found between domains VII and VIII in MAP4Ks, which is identical to the phosphorylation motif of MAPKKs from plants (Jouannic et al., 1999; Ichimura et al., 2002). Both domains participate in peptide-substrate recognition (Champion et al., 2004). MAP4Ks can be linked to the plasma membrane through association with a small GTPase or lipid (Qi and Elion, 2005). They are directly activated by stimulated interaction with adaptor proteins (Qi and Elion, 2005). The MAP4Ks are divided into eight classes including PAK-related, Gck, Mst, Tao, Ste/PAK, Sok (Champion et al., 2004). The majority of MAP4Ks are from the large class of Ste20 protein kinases, which exhibit a highly diverse noncatalytic domain (Dan et al., 2001). The PAKs, which have a C-terminal catalytic domain, are separated from the GC Kinase-related polypeptides, which contain an N-terminal catalytic domain (Dan et al., 2001). Most of the MAP4Ks contain an N-terminal catalytic domain, but members of the STE20/PAK group have a C-terminal kinase domain and some plant MAP4Ks have their kinase domain in the middle of the sequences (Leprince et al., 1999). The Arabidopsis genome contains 10 putative MAP4Ks (Champion et al., 2004). A maize gene encoding MIK is a GCKlike kinase being a subfamily of MAP4K (Llompart et al., 2003), 
which relates membrane-located receptors to MAP kinases (Dan et al., 2001). Some MAP4K are able to phosphorylate MEKK or Raf members whereas other MAP4Ks either phosphorylate MAPKKs or function as adaptors (Champion et al., 2004).

However, the functions of most MAPK genes in plants are still unknown. Although MAPK cascades are involved in signaling multiple defense responses, the role of Vitis MAPK cascades in response to biotic and abiotic stresses are not elucidated. In previous studies in grapevine, a few components of the MAPK gene family were isolated (Wang et al., 2014a). In addition, the gene family of MAPKKKs were identified and their expression profiles were analyzed in different organs in response to different stresses (Wang et al., 2014b). Interestingly, the expression of $V v M A P$ kinase gene was induced by salinity and drought (Daldoul et al., 2012). However, the MAPKK and the MAPKKKK subfamilies have not yet been characterized. To explore the role of MAPK cascade proteins in biotic and abiotic stress responses in grapevine, the publicly available grapevine genome (Jaillon et al., 2007) was analyzed to identify all members of MAPK cascade proteins. Using these databases, we characterized all members of MAPK cascades of $V$. vinifera and performed a phylogenetic analysis in comparison with members of Arabidopsis MAPK cascade proteins.

\section{Materials and Methods}

\section{Genome-wide Identification of MAPK Cascade Genes in Grapevine}

The MAPK cascade protein sequences of Arabidopsis thaliana were used to search against the $V$. vinifera proteome $12 \times$ database (http://www.genoscope.cns.fr/externe/ GenomeBrowser/Vitis/) using a BLASTP analysis (http://www. ncbi.nlm.nih.gov/blast) (Altschul et al., 1990) with scores higher than 400 and an "E" value > e-120 (Çakır and Kılıçkaya, 2013). The sequences of Arabidopsis MAPK cascade proteins were obtained from the TAİ (http://www.arabidopsis.org/). MAPK domain (PS01351), ATP-binding domain (PS00107), protein kinase domain (PS50011), serine/threonine protein kinase active site (PS00108) were identified in the sequences of polypeptides corresponding to $V$. vinifera MAPK cascade proteins by the Conserved Domain Database (CDD) at NCBI (http://www.ncbi. nlm.nih.gov/Structure/cdd/wrpsb.cgi) and PROSITE (http:// prosite.expasy.org/) (Marchler-Bauer et al., 2009). In addition, the NCBI non-redundant protein database was screened with each sequence in order to independently validate the automatic annotation.

\section{Multiple-sequence Alignment and Phylogenetic Tree Construction}

Multiple-sequence alignments of the putative MAPK cascade proteins were aligned using CLUSTAL $\mathrm{W}$ and subjected to phylogenetic analysis by both the maximum parsimony and distance with neighbor-joining methods with 1000 bootstrap replicates (Saitou and Nei, 1987; Thompson et al., 1994). The phylogenetic tree was illustrated using MEGA5. Because similar results were obtained with both methods, only the single tree retrieved from the distance analysis is discussed in detail.
For MAPK cascade subfamilies from both $V$. vinifera and $A$. thaliana, multiple sequence alignment was performed using the multiple sequence comparison by log-expectation (MUSCLE) alignment tool (http://www.ebi.ac.uk/Tools/msa/ muscle/) (Edgar, 2004). The phylogenetic analysis was performed using a neighbor-joining method with 1000 bootstrap replicates andvisualized with MEGA5 software (Tamura et al., 2011). The protein theoretical molecular weight and isoelectric point were predicted using compute $\mathrm{pI} / \mathrm{MW}$ (http://au.expasy.org/tools).

\section{Orthology Analysis and Database Search}

Orthology analysis was performed using the PHOG web server (http://phylofacts.berkeley.edu/orthologs/) (Datta et al., 2009). The sequences of conserved domains with similarity over $70 \%$ and an "E" value of 0.0 were selected as queries. The selected sequences of conserved domains from different species were then used in a BLASTP search against the $V$. vinifera protein sequence database. The best hits were annotated as putative orthologous sequences (Moreno-Hagelsieb and Latimer, 2008).

Expressed sequence tags (ESTs) were identified by BLASTn of the $V$. vinifera expressed sequence tag (EST) database (http:// www.ncbi.nlm.nih.gov/dbEST). Using the sequences of all of the MAPK cascade proteins as queries. The positives sequences were then confirmed by alignment with the query ORF.

\section{Results and Discussion}

\section{Genome-wide Identification of MAPK Cascade Genes in Vitis vinifera}

Vitis vinifera MAPK cascade sequences were mined from the grapevine genome proteome 12x database (Jaillon et al., 2007). We identified 88 ORFs encoding putative MAPK cascade proteins containing at least MAPK domain by BLAST searches of the grapevine genome proteome $12 \times$ database with the amino acid sequences of the MAPK cascade proteins from $A$. thaliana as queries (Table 1). The completed Vitis genome contains 14 MAPKs, 5 MAPKKs, 62 MAPKKKs, and 7 MAPKKKKs (Table 1).

\section{Phylogenetic Analysis}

All predicted MAPK cascade family sequences were aligned using ClustalW (Thompson et al., 1994). A rooted phylogenetic tree was constructed by alignment of full length amino acid sequences using the MEGA5 program and maximum parsimony and distance with neighbor-joining methods (Saitou and Nei, 1987) (Figure 1). One thousand bootstrap replicates were produced for each analysis.

Vitis MAPK cascade sequences can be divided into four subfamilies on the basis of the presence of conserved threonine and tyrosine residues in the motif TxY located in the activation loop (T-loop) between kinase subdomains VII and VIII. In addition, we identified MAPKKKK subfamily with 7 members in Vitis genome, which has the conserved amino acid motifs TFVGTPxWMAPEV as described (Jonak et al., 2002). The members of four subfamilies clustered more tightly with each other than with members of other subfamilies (Figure 1). 


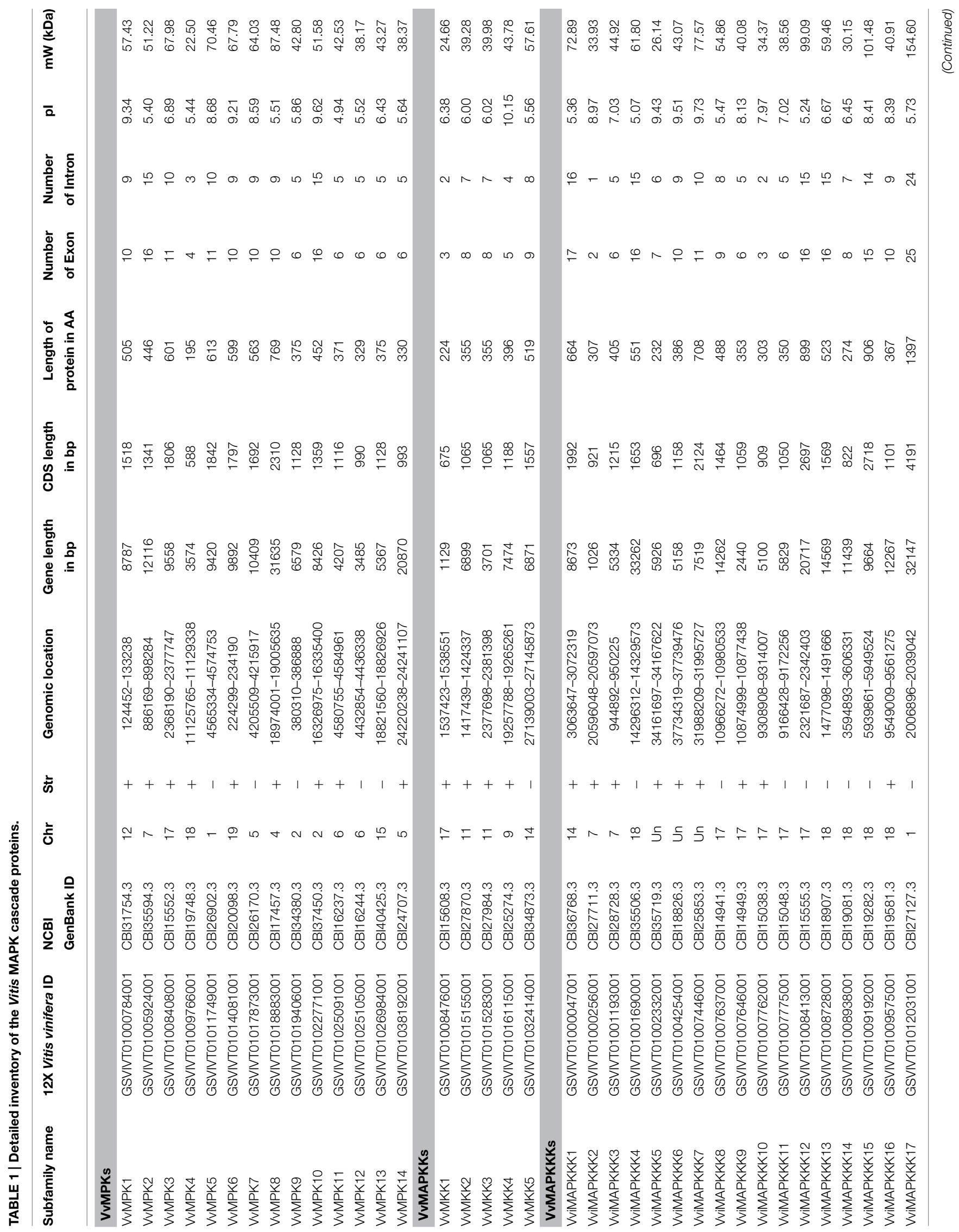




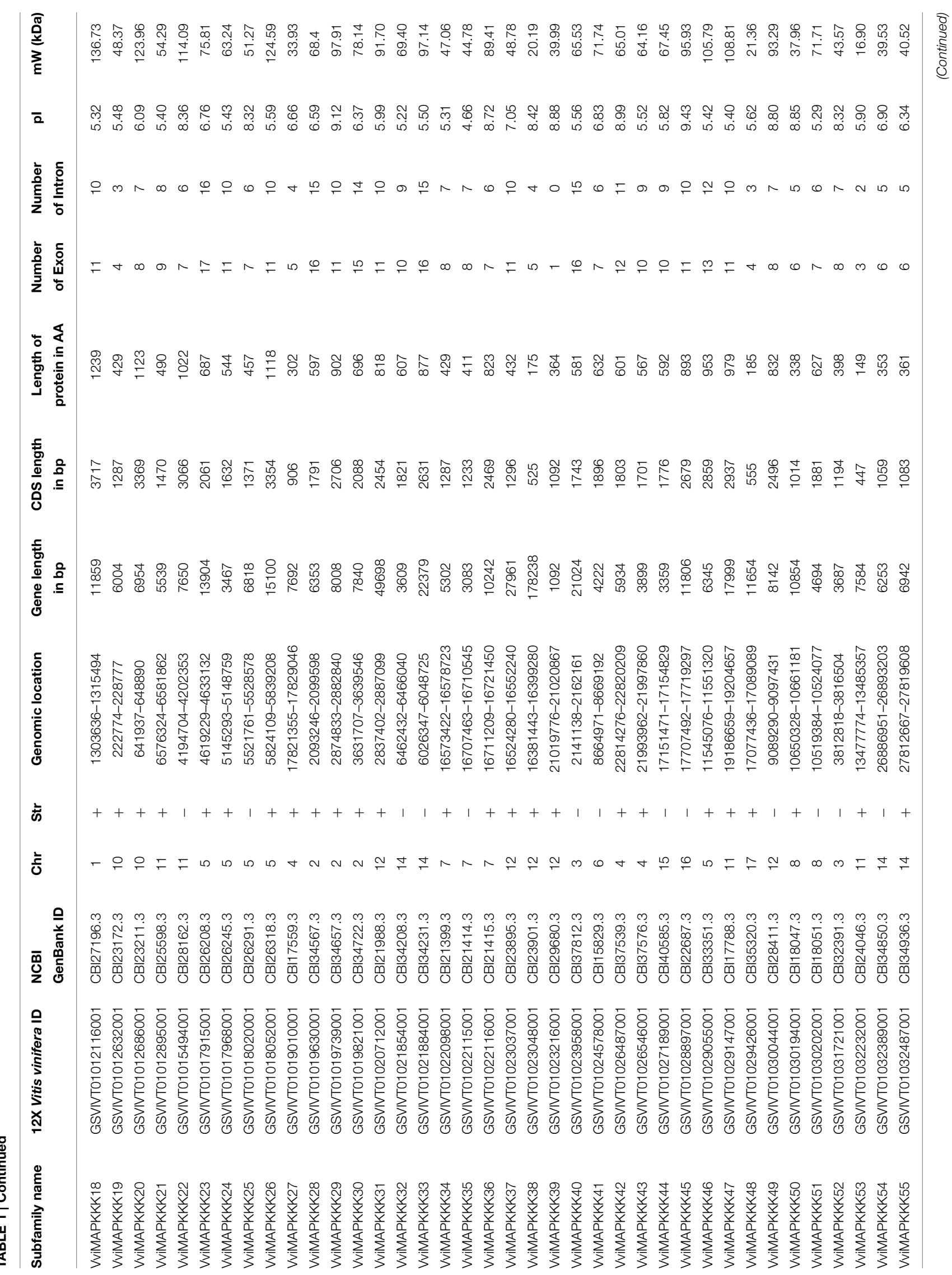




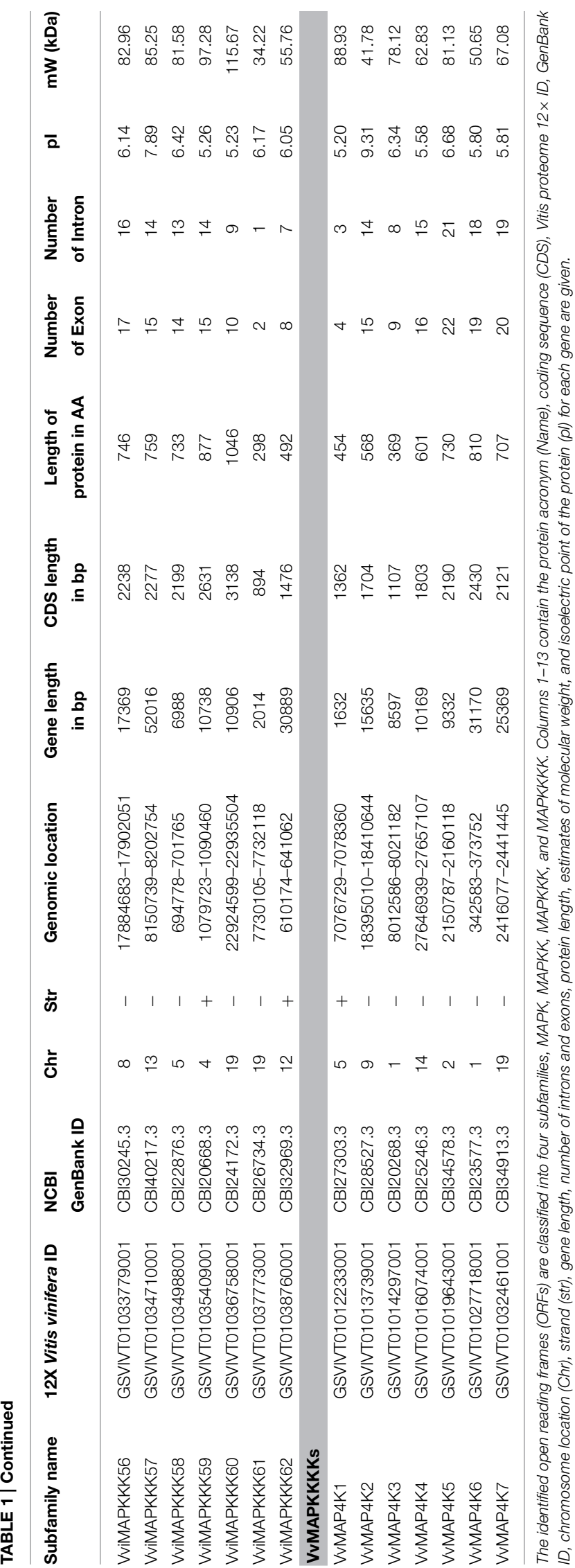

\section{MAPKs}

The phylogenetic analysis showed that the VvMAPKs were devided into five distinct groups, which is higher than previous reports (Kumar and Kirti, 2010; Nadarajah and Sidek, 2010). Group V MAPKs are found only in the grapevine genome among other plant species. All of identified ORFs encoding MAPK were named VvMPK1 through 14. Hyun et al. (2010) reported 12 MAPKs based on $8 \mathrm{x}$ sequence coverage in grapevine genome whereas we identified a total of 14 ORFs in Vitis 12x genome coverage (Hyun et al., 2010), which may be due to the errors corrected in 12x genome sequence coverage. The grapevine genome contains less MAPKs than Arabidopsis (20 MAPKs) (Ichimura et al., 2002) and rice (17 MAPKs) (Liu and Xue, 2007). Members of the Vitis MAPK subfamily show $20-86 \%$ identity to each other. Full length MAPK proteins ranged in size from 195 to 769 amino acids (Table 1). Variation in length of the entire MAPK gene is usually due to differences in the length of MAPK domain and/or, due to the number of introns. The difference in length among MAPK genes may indicate the presence or absence of motifs which could affect functional specifity.

VvMPK12, VvMPK14 belong to the group I., which contains well-characterized MAPK genes including AtMPK3, AtMPK6 (Figure 2). It has been demonstrated that AtMPK3, OsMPK5 were activated in response to pathogens and abiotic stresses (Zhang and Klessig, 2001; Hamel et al., 2006; Rohila and Yang, 2007). OsMPK5 plays an important role for the resistance to blast disease (Song and Goodman, 2002; Huang et al., 2011). AtMPK6 can be activated by various abiotic and biotic stresses (Ichimura et al., 2000; Yuasa et al., 2001; Feilner et al., 2005; Huang et al., 2011). Similarly, PtrMAPK is involved in resistance to both dehydration and cold (Huang et al., 2011).

Group II MAPKs are involved in both abiotic stresses and cell division in Arabidopsis. VvMPK13, VvMPK11, and VvMPK9 are clustered with Group II., which includes AtMPK4, AtMPK5, AtMPK12, and AtMPK11. AtMPK4 and its upstream MAPKK AtMKK2 can be activated by biotic and abiotic stresses (Ichimura et al., 2000; Teige et al., 2004).

VvMPK4 and VvMPK8 belong to group III. AtMPK1 in the group III is regulated by salt stress treatment (Mizoguchi et al., 1996). In addition, AtMPK1 and AtMPK2 are activated by ABA (Ortiz-Masia et al., 2007). The group III genes, such as rice BWMK1 and alfalfa TDY1, are activated by wounding and pathogens (Nowak et al., 1997; Lynch et al., 2001).

Group IV, which includes VvMPK1, VvMPK3, VvMPK5, VvMPK6, and VvMPK7 of the Vitis MAPKs, have the TDY motif in their T-loop and the absence of the C-terminal CD domain, which is consistently found in members of the other MAPK groups. VvMPK2 and VvMPK10 belonging to group V were separated from other groups.

The orthology analysis program identified one hundredfourteen orthologs from various plant species for this subfamily (Table 2). The VvMPK3 amino acid sequence shows $83 \%$ similarity with AtMPK9, and VvMPK12 shows 84\% similarity with AtMPK3 from A. thaliana. The members of VvMAPK subfamily share between 75.8 and $91.8 \%$ similarity to the MAPK members from Ricius communis, 


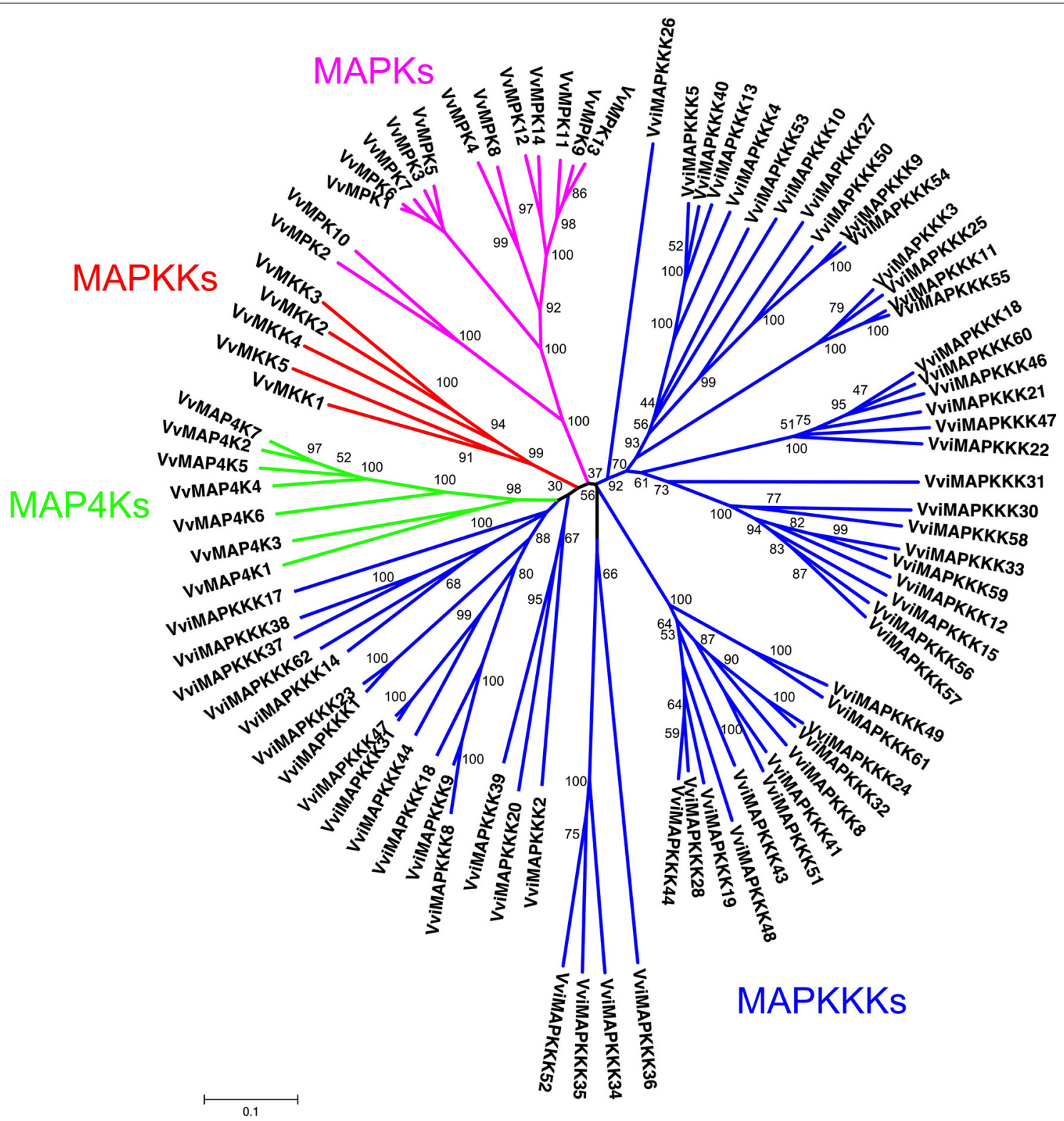

FIGURE 1 | Construction of phylogenetic tree of Vitis MAPK cascade proteins. The amino sequences of all Vitis $A B C$ proteins were aligned using the ClustalW program and were subjected to phylogenetic analysis by the distance with neighbor-joining method. The reliabilities of each branch point, as assessed by the analysis of 1000 computer-generated trees (bootstrap replicates), were in excess of $90 \%$, except for those discussed in the text. The abbreviations of MAPK cascade proteins are as follows: MAPK, Mitogen-activated Protein Kinase; MAPKK, MAPK Kinase; MAPKKK, MAPKK Kinase; MAPKKKK, MAPKKK Kinase as described in the text.
Oryza sativa, and A. thaliana. The phylogenetic analysis of $A$. thaliana and $V$. vinifera MAPK subfamilies confirmed the orthologs of VvMPK14/AtMPK6, VvMPK12/AtMPK3, VvMAPK11/AtMAPK13, VvMPK13/AtMPK12, VvMPK7/AtMPK16, and VvMPK3/AtMPK9 (Figure 2).

All of the 14 Vitis MAPK proteins are represented in the Vitis ESTs database (Supplementary Table 1) and are expressed in different tissues such as fruits, berries, buds, flowers, leaves, and roots. In addition, $12 V v M P K$ genes were isolated (Wang et al., 2014a). Expression analysis of $V v M P K$ genes showed that all $V v M P K$ genes are expressed during grapevine growth and development, and in biotic and abiotic stresses (Wang et al., 2014a).

\section{MAPKKs}

This subfamily consists of 10 members in Arabidopsis genome (Group et al., 2002), whereas Vitis genome contains 5 members of MAPKK subfamily. The full length VvMKK sequences range in size from 224 to 519 amino acids (Table 1). The members of the MAPKK subfamily in the Vitis genome share 29-40\% 


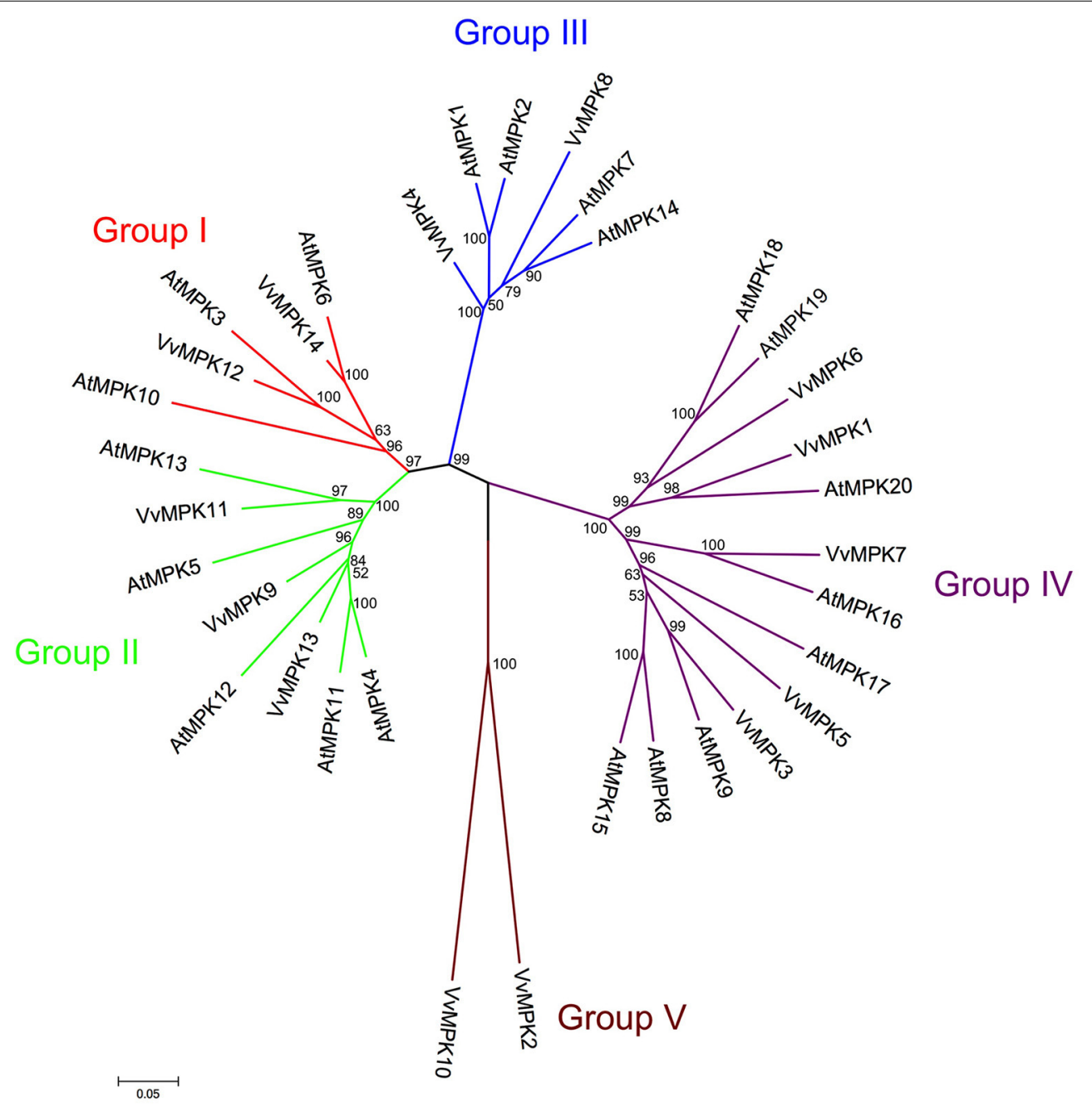

FIGURE 2 | Phylogenetic relationship of Arabidopsis and Vitis MAPK proteins. The amino acid sequences of all Arabidopsis MAPK proteins and those of Vitis vinifera were aligned using the MUSCLE program and subjected to phylogenetic analysis by the distance with neighborjoining method using MEGA5 programme. Accession numbers for Arabidopsis sequences are AtMPK1 (At1g10210), AtMPK2 (At1g59580), AtMPK3
(At3g45640), AtMPK4 (At4g01370), AtMPK5 (At4g11330), AtMPK6 (At2g43790), AtMPK7 (At2g18170), AtMPK8 (At1g18150), AtMPK9 (At3g18040), AtMPK10 (At3g59790), AtMPK11 (At1g01560), AtMPK12 (At2g46070), AtMPK13 (At1g07880), AtMPK14 (At4g36450), AtMPK15 (At1g73670), AtMPK16 (At5g19010), AtMPK17 (At2g01450), AtMPK18 (At1g53510), AtMPK19 (At3g14720), AtMPK20 (At2g42880). similarity with each other. By phylogenetic analysis, we also identified orthologs of Vitis MAPKKs in Arabidopsis such as VvMKK5/AtMKK3 (78.6\% similarity), VvMKK3/AtMKK6 (83.1\% similarity), and VvMKK2/AtMKK2 (70.4\% similarity) supported with significant bootstrap values. The phylogenetic analysis confirmed that VvMKK3 shares $83.3 \%$ similarity with its homolog from Arabidopsis on the basis of orthology analysis, (Figure 3, Table 2).

To date, none of the Vitis MAPKK homologs have been cloned or characterized. However, 98 ESTs were identified for this subfamily in different tissues in response to biotic or abiotic stresses (Supplementary Table 2). A role of MAPK kinase, MKK1 in abiotic stress signaling was previously demonstrated (Matsuoka et al., 2002). Analysis of MKK1 revealed that drought, salt stress, cold, wounding activated MKK1, which in turns activates its downstream target MPK4 (Matsuoka et al., 2002). Tobacco NtMEK2 is functionally interchangeable with two Arabidopsis MAPKKs, AtMKK4, and AtMKK5 in activating the downstream MAPKs (Ren et al., 2002). MdMKK1 was reported to be downregulated by ABA (Wang et al., 2010). In Arabidopsis, AtMKK3 is upregulated in response to ABA (Hwa and Yang, 2008). Interestingly, AtMKK1/AtMKK2 play an important role in signaling in ROS homeostasis (Liu, 2012).

\section{MAPKKKs}

With 62 members, the MAPKKK subfamily represents the largest subfamily of $V$. vinifera MAPK cascade proteins, which is smaller than those of Arabidopsis ( 80 members) and rice (75 members) (Colcombet and Hirt, 2008; Rao et al., 2010). Recently, Wang et al. (2014b) identified 45 MAPKKK genes in grapevine $12 \mathrm{x}$ 
TABLE 2 | Orthologs of Vitis MAPK cascade proteins identified in diverse plant species.

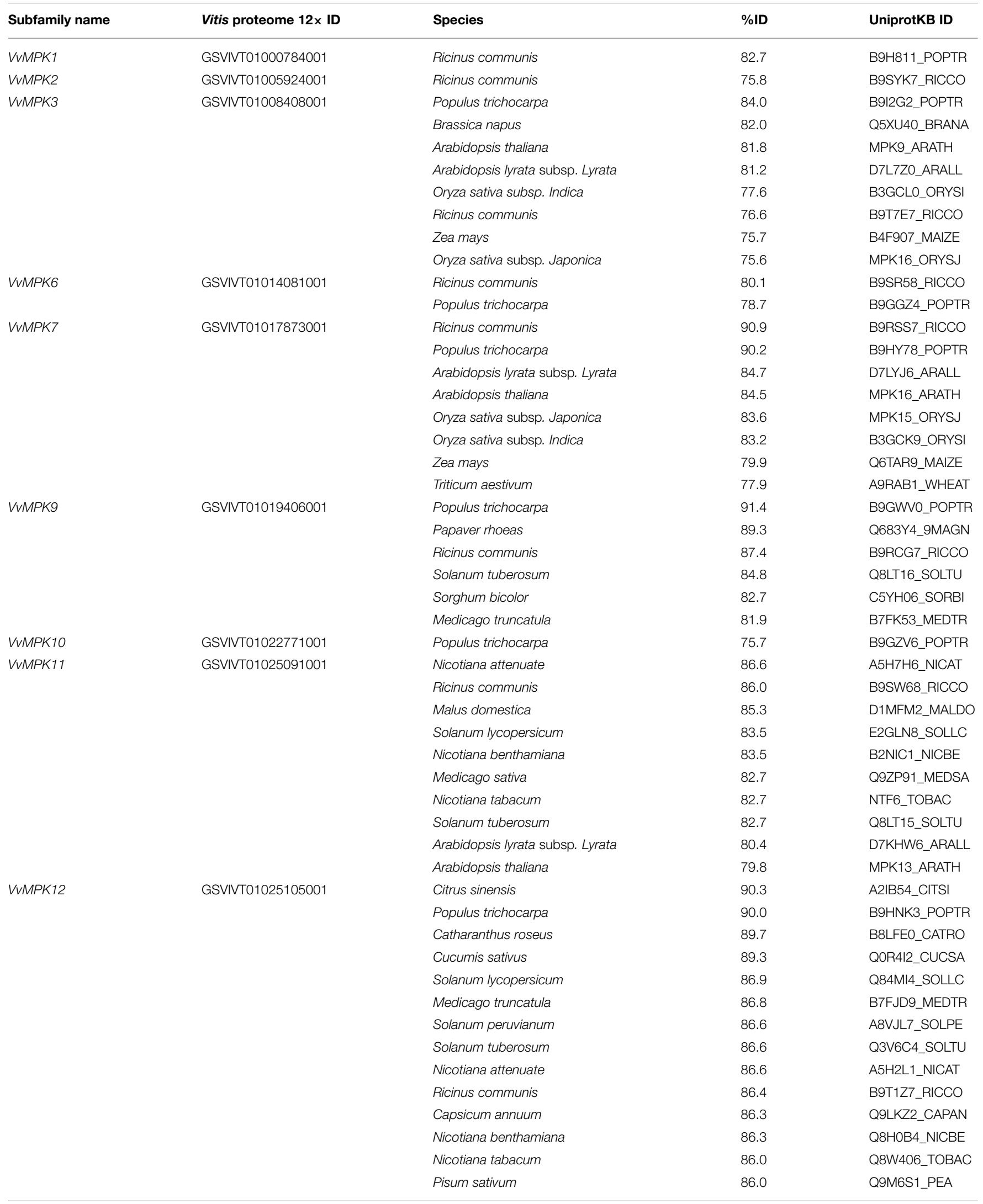


TABLE 2 | Continued

\begin{tabular}{|c|c|c|c|c|}
\hline Subfamily name & Vitis proteome $12 \times$ ID & Species & $\%$ ID & UniprotKB ID \\
\hline & & Brassica napus & 86.0 & Q5IV18_BRANA \\
\hline & & Medicago sativa & 85.7 & O24077_MEDSA \\
\hline & & Petroselinum crispum & 85.7 & O04694_PETCR \\
\hline & & Glycine max & 85.4 & Q5K6Q4_SOYBN \\
\hline & & Arabidopsis thaliana & 84.2 & MPK3_ARATH \\
\hline & & Avena sativa & 77.3 & Q43379_AVESA \\
\hline \multirow[t]{15}{*}{ VVMPK13 } & GSVIVT01026984001 & Nicotiana attenuate & 90.7 & A5H7H4_NICAT \\
\hline & & Ricinus communis & 90.5 & B9RDW5_RICCO \\
\hline & & Glycine max & 89.9 & C6TEPO_SOYBN \\
\hline & & Populus trichocarpa & 89.2 & B9GQC1_POPTR \\
\hline & & Solanum lycopersicum & 88.2 & D7R517_SOLLC \\
\hline & & Thellungiella halophile & 87.4 & E4MW58_THEHA \\
\hline & & Brassica napus & 87.3 & E3US78_BRANA \\
\hline & & Arabidopsis thaliana & 87.2 & MPK4_ARATH \\
\hline & & Arabidopsis lyrata subsp. Lyrata & 86.9 & D7M4W5_ARALL \\
\hline & & Malus micromalus & 86.4 & Q8GZR5_MALMI \\
\hline & & Medicago sativa & 86.3 & MMK2_MEDSA \\
\hline & & Oryza sativa subsp. Ýndica & 83.6 & A2Z9P1_ORYSI \\
\hline & & Oryza sativa subsp. Japonica & 83.6 & MPK6_ORYSJ \\
\hline & & Zea mays & 83.2 & B4FH09_MAIZE \\
\hline & & Sorghum bicolor & 82.4 & C5WUGO_SORBI \\
\hline \multirow{17}{*}{ VvMPK14 } & & Glycine max & 94.2 & Q5K6N6_SOYBN \\
\hline & & Nicotiana tabacum & 93.3 & NTF4_TOBAC \\
\hline & & Solanum tuberosum & 93.0 & Q8LT17_SOLTU \\
\hline & & Nicotiana benthamiana & 93.0 & B3IWK6_NICBE \\
\hline & & Solanum lycopersicum & 93.0 & Q84MI5_SOLLC \\
\hline & & Capsicum annuum & 92.7 & Q9LKZ1_CAPAN \\
\hline & & Solanum peruvianum & 92.7 & B5B2H6_SOLPE \\
\hline & & Nicotiana attenuate & 92.4 & A5H2LO_NICAT \\
\hline & & Arabidopsis thaliana & 91.8 & MPK6_ARATH \\
\hline & & Arabidopsis lyrata subsp. Lyrata & 91.8 & D7LKI6_ARALL \\
\hline & & Brassica napus & 91.5 & E1B2J5_BRANA \\
\hline & & Sorghum bicolor & 90.9 & C5Z4D1_SORBI \\
\hline & & Oryza sativa subsp. Japonica & 90.5 & MPK1_ORYSJ \\
\hline & & Zea mays & 90.5 & B8QN51_MAIZE \\
\hline & & Oryza sativa subsp. Indica & 90.5 & B3GCK7_ORYSI \\
\hline & & Triticum aestivum & 89.9 & Q84XZ3_WHEAT \\
\hline & & Pinus tadea & 87.5 & C7ENI3_PINTA \\
\hline VVMPKK2 & GSVIVT01015155001 & Populus trichocarpa & 81.7 & B9|KC3_POPTR \\
\hline
\end{tabular}


TABLE 2 | Continued

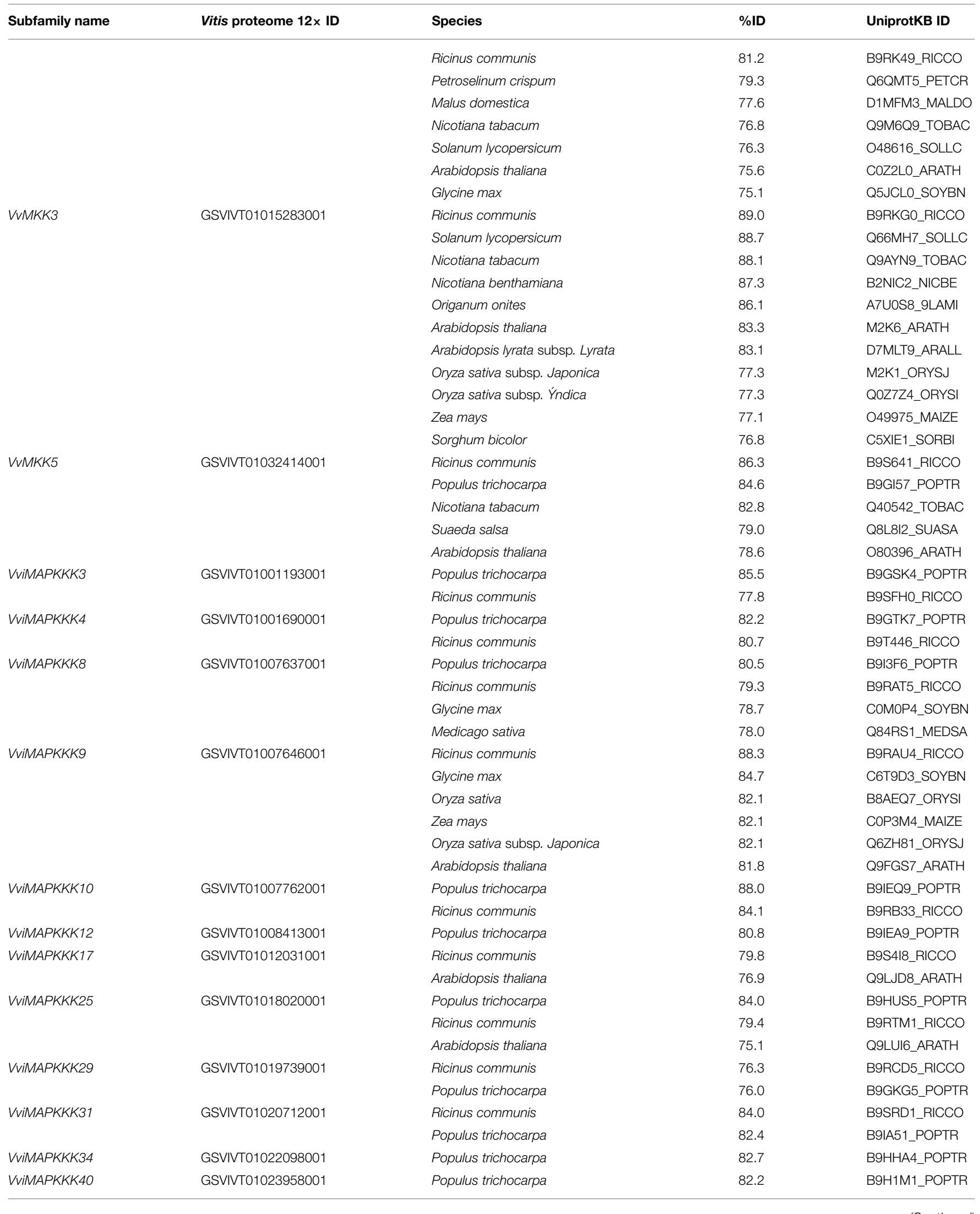


TABLE 2 | Continued

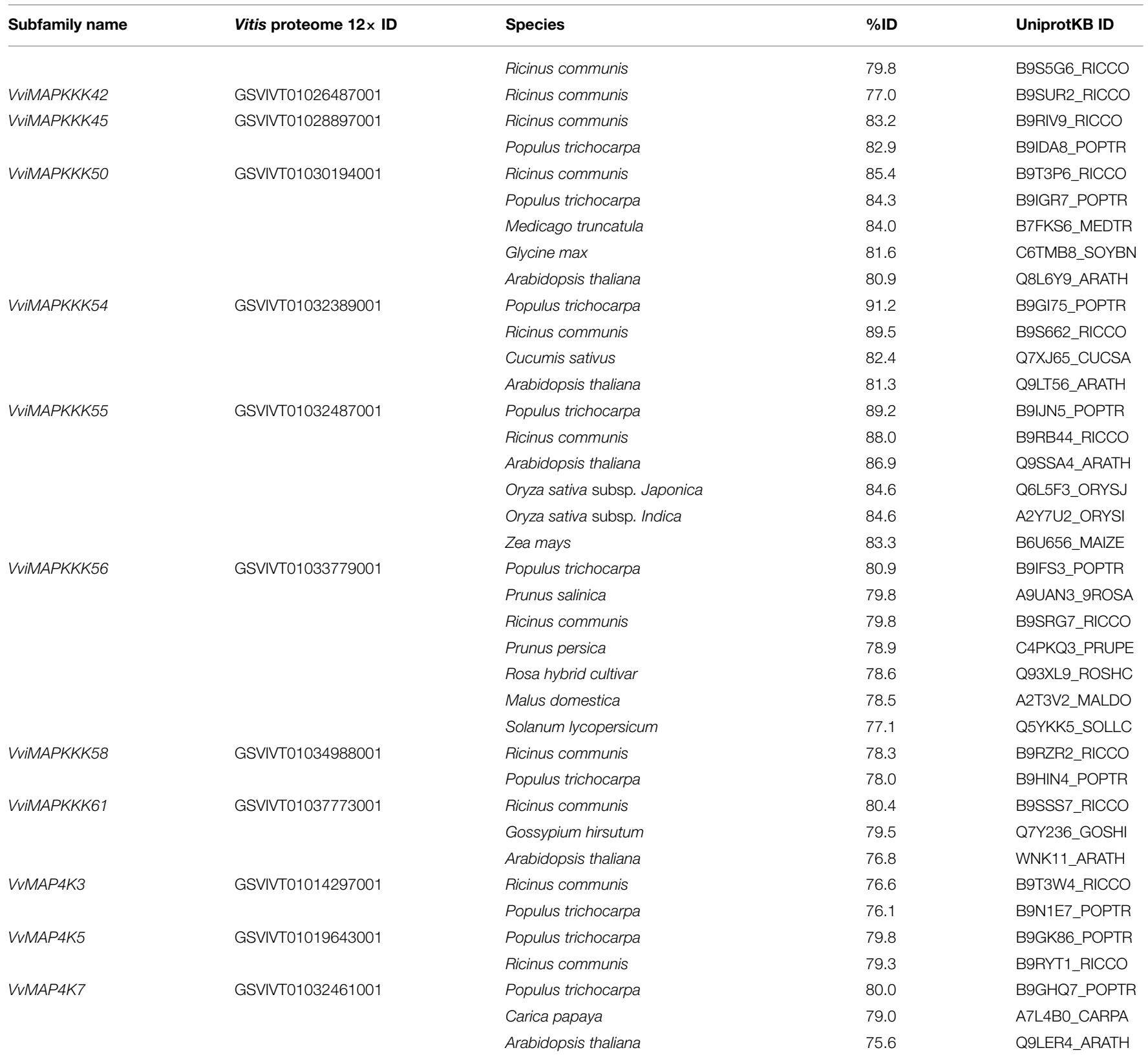

Columns 1-4 contain the protein name, Vitis proteome $12 \times I D$, GenBank ID, species, percentage identity (\%ID), UniprotKB ID.

genome coverage (Wang et al., 2014b). The difference in the number of MAPKKK members in grapevine genome may be related to the "E" value $>\mathrm{E}-120$ used in this report, which is more significant. In addition, domain scan using two different databases (PROSITE and CDD) can identify more sequences in the grapevine genome.

The members of the Vitis MAPKKK subfamily share 11$35 \%$ identity with each other and distributed on various chromosomes (from 2 to 18) (Table 1). The full length Vitis MAPKKK sequences range from 175 (VviMAPKKK38) to 1397 (VviMAPKKK17) amino acids. The phylogenetic analysis of both Vitis and Arabidopsis MAPKKK sequences shows that this subfamily is categorized into three main groups with bootstrap values up to $93 \%$ (Figure 4).

The first group contains MAPKKKs whose kinase domains have similarity to MEKK subfamily members (Figure 4) (Jonak et al., 2002). A second group includes Raf subfamily members while a third group presents ZIK subfamily members (Figure 4) (Jonak et al., 2002). In total, there are 21 VviMAPKKKs in the MEKK subfamily, while there are 12 in the ZIK subfamily and 29 in the Raf subfamily among the 62 members in the Vitis genome. 


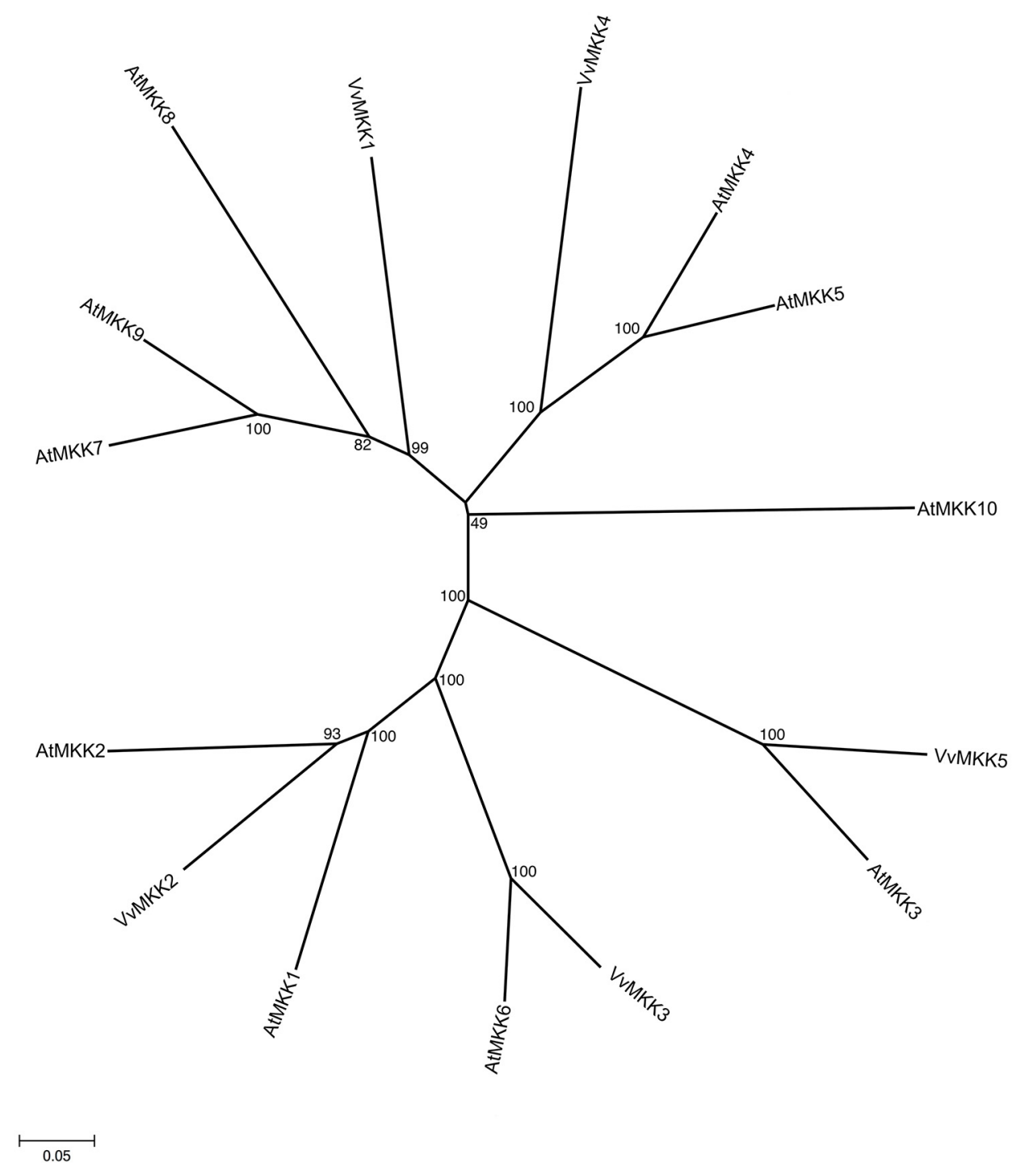

FIGURE 3 | Phylogenetic tree of MAPKK protein sequences from Arabidopsis and Vitis vinifera. The amino acid sequences of all Arabidopsis MAPKK proteins and those of Vitis vinifera were aligned using the MUSCLE program and subjected to phylogenetic analysis by the distance with neighborjoining method using MEGA5

Analysis of conserved domain of VviMAPKKKs identified a long regulatory domain in the $\mathrm{N}$-terminal region and a kinase domain in the C-terminal region in most of VviMAPKKKs. It is suggested that the long regulatory domain in the $\mathrm{N}$-terminal region of the Raf subfamily may be involved in protein-protein interactions and regulate or specify their kinase activity (Jouannic et al., 1999). Twenty members of the Vitis MAPKKK subfamily share $75.1-89.2 \%$ similarity with their orthologs from different plant species (Table 2).

We identified at least 640 ESTs for 59 of the Vitis MAPKKKs (Supplementary Table 3) indicating that MAPKKK subfamily is transcriptionally active. Expression profile of VviMAPKKK genes suggested that some of them are involved in response to biotic and abiotic stresses in different tissues and organs (Wang et al., programme. Accession numbers for Arabidopsis sequences are AtMKK1 (At4g26070), AtMKK2 (At4g29810), AtMKK3 (At5g40440), AtMKK4 (At1g51660), AtMKK5 (At3g21220), AtMKK 6 (At5g56580), AtMKK7 (At1g18350), AtMKK8 (At3g06230), AtMKK9 (At1g73500), AtMKK10 (At1g32320).

2014b). In support of a role for some Vitis MAPKKKs, AtMEKK1 expression is enhanced by drought, salt, stress (Mizoguchi et al., 1996). Recently, it was reported that AtMKK1/MKK2 and AtMEKK1 were able to negatively regulate programmed cell death (PCD) as well as immune responses (Kong et al., 2012). In tobacco, NPK1-MEK1-Ntf6 are also involved in resistance to tobacco mosaic virus (TMV) (Jin et al., 2002; Liu et al., 2004). In addition, AtEDR1, a Raf-like MAPKKK could regulate SA-inducible defense responses negatively (Frye et al., 2001).

\section{MAPKKKKs}

In non-plants, MAPKKKs are activated either through phosphorylation by MAPKKK kinase (MAPKKKK or MAP4K) (Posas and Saito, 1997; Sells et al., 1997) or by G protein and G 


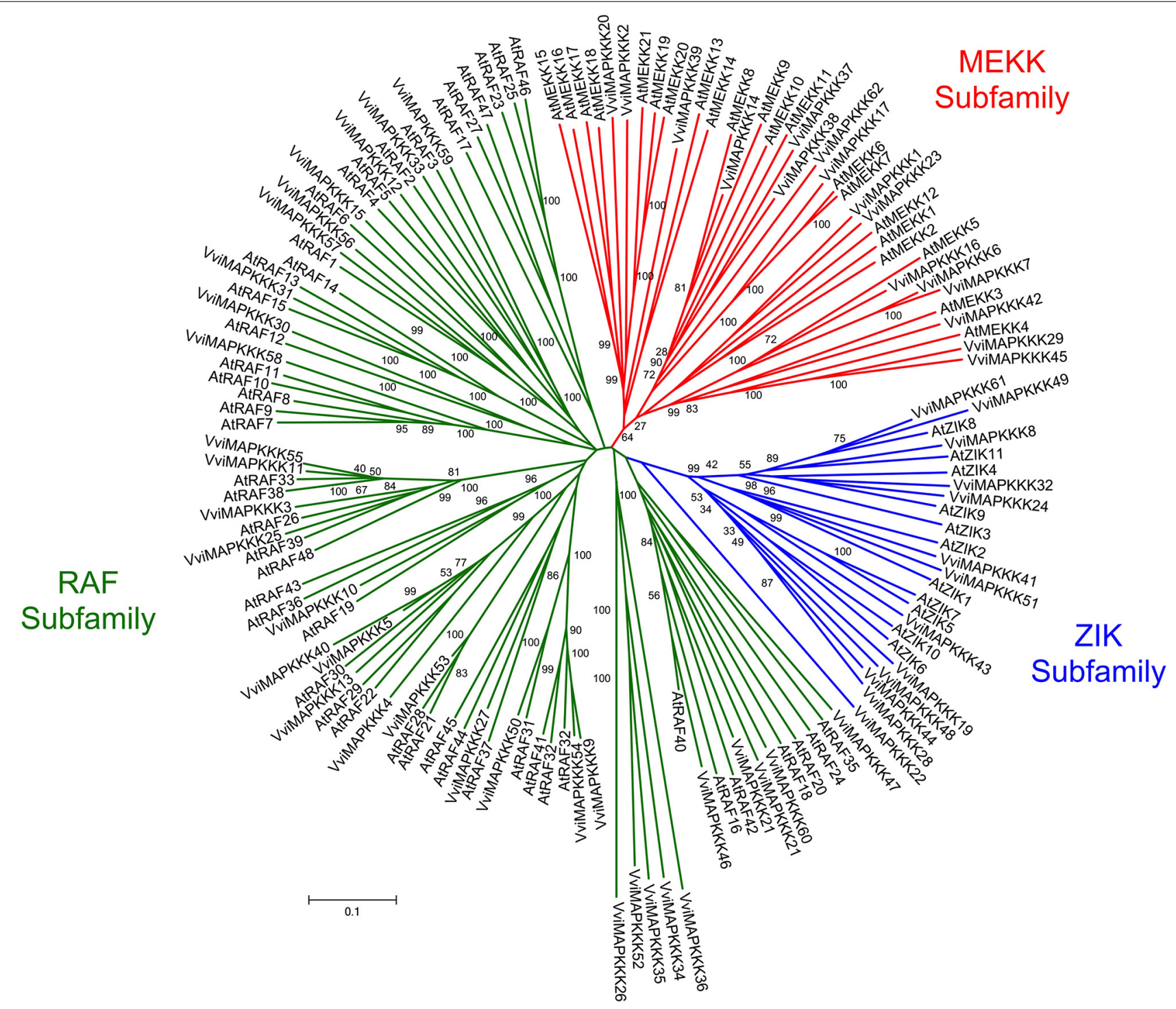

FIGURE 4 | Phylogenetic tree of MAPKKK protein sequences from Arabidopsis and Vitis vinifera. The amino acid sequences of all Arabidopsis MAPKKK proteins and those of Vitis vinifera were aligned using the MUSCLE program and subjected to phylogenetic analysis by the distance with neighborjoining method using MEGA5 programme. MAPKKK forms the largest group of MAPK cascades with 62 members classified into three subfamilies, MEKK, Raf, and ZIK containing 21, 29, and 12 genes, recpectively in Vitis genome. Accession numbers for Arabidopsis sequences are AtMEKK1 (At1g09000), AtMEKK2 (At1g54960), AtMEKK3 (At1g53570), AtMEKK4 (At1g63700), AtMEKK5 (At5g66850), AtMEKK6 (At3g07980), AtMEKK7 (At3g13530), AtMEKK8 (At4g08500), AtMEKK9 (At4g08480), AtMEKK10 (At4g08470), AtMEKK11 (At4g12020), AtMEKK12 (At3g06030), AtMEKK13 (At1g07150), AtMEKK14 (At2g30040), AtMEKK15 (At5g55090), AtMEKK16 (At4g26890), AtMEKK17 (At2g32510), AtMEKK18 (At1g05100), AtMEKK19 (At5g67080), AtMEKK20 (At3g50310), AtMEKK21 (At4g36950), AtRAF1 (At5g03730), AtRAF2 (At1g08720), AtRAF3 (At5g11850), AtRAF4 (At1g18160), AtRAF5 (At1g73660), AtRAF6
(At4g24480), AtRAF7 (At3g06620), AtRAF8 (At3g06630), AtRAF9 (At3g06640), AtRAF10 (At5g49470), AtRAF11 (At1g67890), AtRAF12 (At4g23050), AtRAF13 (At2g31010), AtRAF14 (At2g42630), AtRAF15 (At3g58640), AtRAF16 (At1g04700), AtRAF17 (At1g14000), AtRAF18 (At1g16270), AtRAF19 (At1g62400), AtRAF20 (At1g79570), AtRAF21 (At2g17700), AtRAF22 (At2g24360), AtRAF23 (At2g31800), AtRAF24 (At2g35050), AtRAF25 (At2g43850), AtRAF26 (At4g14780), AtRAF27 (At4g18950), AtRAF28 (At4g31170), AtRAF29 (At4g35780), AtRAF30 (At4g38470), AtRAF31 (At5g01850), AtRAF32 (At5g40540), AtRAF33 (At5g50000), AtRAF34 (At5g50180), AtRAF35 (At5g57610), AtRAF36 (At5g58950), AtRAF37 (At5g66710), AtRAF38 (At3g01490), AtRAF39 (At3g22750), AtRAF40 (At3g24720), AtRAF41 (At3g27560), AtRAF42 (At3g46920), AtRAF43 (At3g46930), AtRAF44 (At3g50720), AtRAF45 (At3g50730), AtRAF46 (At3g59830), AtRAF47 (At3g58760), AtRAF48 (At3g63260), AtZIK1 (At3g51630), AtZIK2 (At5g58350), AtZIK3 (At3g22420), AtZIK4 (At3g04910), AtZIK5 (At3g18750), AtZIK6 (At5g41990), AtZIK7 (At1g49160), AtZIK8 (At5g55560), AtZIK9 (At5g28080), AtZIK10 (At1g64630), AtZIK11 (At3g48260). 


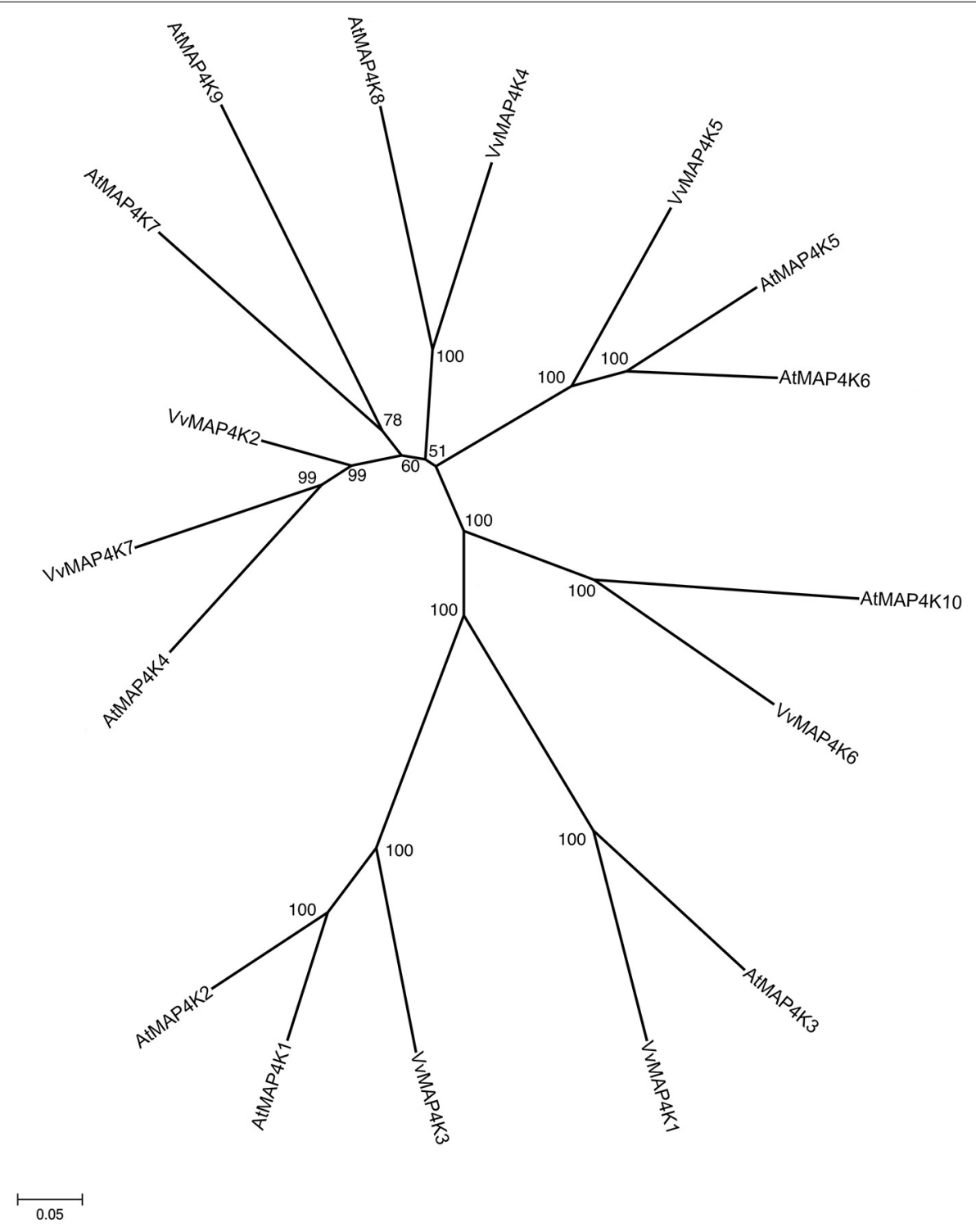

FIGURE 5 | Phylogenetic tree of MAPKKKK protein sequences from Arabidopsis and Vitis vinifera. The amino acid sequences of all Arabidopsis MAPKKKK proteins and those of Vitis vinifera were aligned using the MUSCLE program and subjected to phylogenetic analysis by the distance with neighborjoining method using MEGA5 programme.
Accession numbers for Arabidopsis sequences are AtMAP4K1 (At1g53165), AtMAP4K2 (At3g15220), AtMAP4K3 (At1g69220), AtMAP4K4 (At5g14720), AtMAP4K5 (At4g24100), AtMAP4K6 (At4g10730), AtMAP4K7 (At1g70430), AtMAP4K8 (At1g79640), AtMAP4K9 (At1g23700), AtMAP4K10 (At4g14480). protein-coupled receptors (Fanger et al., 1997; Sugden and Clerk, 1997).

Several MAP4Ks have been identified in plant genomes based on phylogenetic analyses of their kinase domain. A MAP4K, named MIK, was characterized from the Zea mays (Wang et al., 2014d). Recently, a new MAP4K from GCK-II subfamily named ScMAP4K1, which play important roles in ovule, seed, and fruit development was characterized (Major et al., 2009).

In fully sequenced genomes, like Arabidopsis and rice at least 10 protein kinases can be phylogenetically classified as MAP4K (Champion et al., 2004). Little is known about the roles of MAP4Ks in plants. Seven ORFs showing strong similarity with the 10 Arabidopsis MAP4Ks were identified in Vitis genome (Figure 5) and shared 18-74\% similarity with each other. They have been named VvMAP4K1 through 7 (Table 1). The phylogenetic analysis of $V$. vinifera and A. thaliana MAP4Ks proteins identified several orthologs in the two species such as VvMAP4K4/AtMAP4K8 (70\% similarity), VvMAP4K1/AtMAP4K3 (66\% similarity), VvMAP4K7/AtMAP4K4 (68\% similarity), and VvMAP4K6/AtMAP4K10 (64\% similarity) (Figure 5).

In addition, we identified several orthologs from different species for 3 VvMAP4Ks (Table 2). Among 7 ORFs encoding 
Vitis MAP4Ks, all of them are transcriptionally active (Supplementary Table 4), but none of them has been cloned and characterized.

\section{Conclusions}

This report represents the first complete genome-wide analysis of MAPK cascade proteins in grapevine. The identification of Vitis MAPK cascade proteins and their comparative analysis with the Arabidopsis MAPK cascade proteins indicates that MAPK cascade genes have been conserved during evolution. In this report, we annotated 90 ORFs encoding MAPK cascade proteins in $V$. vinifera using a bioinformatics approach. Taken as a whole, our data provide significant insights into future biological and physiological analysis of MAPK cascades from $V$. vinifera.

\section{References}

Altschul, S. F., Gish, W., Miller, W., Myers, E. W., and Lipman, D. J. (1990). Basic local alignment search tool. J. Mol. Biol. 215, 403-410. doi: 10.1016/S00222836(05)80360-2

Asai, T., Tena, G., Plotnikova, J., Willmann, M. R., Chiu, W. L., Gomez-Gomez, L., et al. (2002). MAP kinase signalling cascade in Arabidopsis innate immunity. Nature 415, 977-983. doi: 10.1038/415977a

Bergmann, D. C., Lukowitz, W., and Somerville, C. R. (2004). Stomatal development and pattern controlled by a MAPKK kinase. Science 304, 1494-1497. doi: 10.1126/science.1096014

Bögre, L., Calderini, O., Binarova, P., Mattauch, M., Till, S., Kiegerl, S., et al. (1999). A MAP kinase is cctivated late in plant mitosis and becomes localized to the plane of cell division. Plant Cell 11, 101-113. doi: 10.1105/tpc. 11.1.101

Bush, S. M., and Krysan, P. J. (2007). Mutational evidence that the Arabidopsis MAP kinase MPK6 is involved in anther, inflorescence, and embryo development. J. Exp. Bot. 58, 2181-2191. doi: 10.1093/jxb/ erm092

Çakır, B., and Kılıçkaya, O. (2013). Whole-genome survey of the putative ATPbinding cassette transporter family genes in Vitis vinifera. PLoS ONE 8:e78860. doi: 10.1371/journal.pone.0078860

Cardinale, F., Meskiene, I., Ouaked, F., and Hirt, H. (2002). Convergence and divergence of stress-induced mitogen-activated protein kinase signaling pathways at the level of two distinct mitogen-activated protein kinase kinases. Plant Cell 14, 703-711. doi: $10.1105 /$ tpc.010256

Champion, A., Picaud, A., and Henry, Y. (2004). Reassessing the MAP3K and MAP4K relationships. Trends Plant Sci. 9, 123-129. doi: 10.1016/j.tplants.2004.01.005

Colcombet, J., and Hirt, H. (2008). Arabidopsis MAPKs: a complex signalling network involved in multiple biological processes. Biochem. J. 413, 217-226. doi: $10.1042 / \mathrm{BJ} 20080625$

Daldoul, S., Hoefer, M. II, and Mliki, A. (2012). Osmotic Stress Induces the Expression of VvMAP Kinase Gene in Grapevine (Vitis vinifera L.). J. Bot. 11, 1-4. doi: 10.1155/2012/737035

Dan, I., Watanabe, N. M., and Kusumi, A. (2001). The Ste20 group kinases as regulators of MAP kinase cascades. Trends Cell Biol. 11, 220-230. doi: 10.1016/S0962-8924(01)01980-8

Datta, R. S., Meacham, C., Samad, B., Neyer, C., and Sjolander, K. (2009). Berkeley PHOG: PhyloFacts orthology group prediction web server. Nucleic Acids Res. 37, W84-W89. doi: 10.1093/nar/gkp373

del Pozo, O., Pedley, K. F., and Martin, G. B. (2004). MAPKKK $\alpha$ is a positive regulator of cell death associated with both plant immunity and disease. $E M B O$ J. 23, 3072-3082. doi: 10.1038/sj.emboj.7600283

Edgar, R. C. (2004). MUSCLE: multiple sequence alignment with high accuracy and high throughput. Nucleic Acids Res. 32, 1792-1797. doi: 10.1093/nar/gkh340

\section{Author Contributions}

$\mathrm{BÇ}$ conceived and designed all research. OK performed the bioinformatic analyses. $\mathrm{BC}$ analyzed data and wrote the article.

\section{Acknowledgments}

This work was funded by the Department of Horticulture, Ege University, Turkey.

\section{Supplementary Material}

The Supplementary Material for this article can be found online at: http://journal.frontiersin.org/article/10.3389/fpls.2015. 00556

Fanger, G. R., Johnson, N. L., and Johnson, G. L. (1997). MEK kinases are regulated by EGF and selectively interact with Rac/Cdc42. Embo J. 16, 4961-4972. doi: 10.1093/emboj/16.16.4961

Feilner, T., Hultschig, C., Lee, J., Meyer, S., Immink, R. G. H., Koenig, A., et al. (2005). High throughput identification of potential Arabidopsis mitogenactivated protein kinases substrates. Mol. Cell. Proteomics 4, 1558-1568. doi: 10.1074/mcp.M500007-MCP200

Fiil, B. K., Petersen, K., Petersen, M., and Mundy, J. (2009). Gene regulation by MAP kinase cascades. Cur. Opin. Plant Biol. 12, 615-621. doi: 10.1016/j.pbi.2009.07.017

Frye, C. A., Tang, D., and Innes, R. W. (2001). Negative regulation of defense responses in plants by a conserved MAPKK kinase. Proc. Natl. Acad. Sci. U.S.A. 98, 373-378. doi: 10.1073/pnas.98.1.373

Galletti, R., Ferrari, S., and De Lorenzo, G. (2011). Arabidopsis MPK3 and MPK6 play different roles in basal and oligogalacturonide- or flagellininduced resistance against Botrytis cinerea. Plant Physiol. 157, 804-814. doi: 10.1104/pp.111.174003

Gray, J. E., and Hetherington, A. M. (2004). Plant development: YODA the stomatal switch. Curr. Biol. 14, R488-R490. doi: 10.1016/j.cub.2004.06.019

Group, M., Ichimura, K., Shinozaki, K., Tena, G., Sheen, J., Henry, Y., Champion, A., et al. (2002). Mitogen-activated protein kinase cascades in plants: a new nomenclature. Trends Plant Sci. 7, 301-308. doi: 10.1016/S13601385(02)02302-6

Hamel, L. P., Nicole, M. C., Sritubtim, S., Morency, M. J., Ellis, M., Ehlting, J., et al. (2006). Ancient signals: comparative genomics of plant MAPK and MAPKK gene families. Trends Plant Sci. 11, 192-198. doi: 10.1016/j.tplants.2006.02.007

Huang, X., Luo, T., Fu, X., Fan, Q., and Liu, J. (2011). Cloning and molecular characterization of a mitogen-activated protein kinase gene from Poncirus trifoliata whose ectopic expression confers dehydration/drought tolerance in transgenic tobacco. J. Exp. Bot. 62, 5191-5206. doi: 10.1093/jxb/err229

Huttly, A. K., and Phillips, A. L. (1995). Gibberellin-regulated expression in oat aleurone cells of two kinases that show homology to MAP kinase and a ribosomal protein kinase. Plant Mol. Biol. 27, 1043-1052. doi: 10.1007/bf00037031

Hwa, C.-M., and Yang, X.-C. (2008). The AtMKK3 pathway mediates ABA and salt signaling in Arabidopsis. Acta Physiol. Plantarum 30, 277-286. doi: 10.1007/s11738-007-0117-3

Hyun, T. K., Kim, J. S., Kwon, S. Y., and Kim, S. H. (2010). Comparative genomic analysis of mitogen activated protein kinase gene family in grapevine. Genes Genomics 32, 275-281. doi: 10.1007/s13258-010-0010-0

Ichimura, K., Mizoguchi, T., Irie, K., Morris, P., Giraudat, J., Matsumoto, K., et al. (1998). Isolation of ATMEKK1 (a MAP kinase kinase kinase)-interacting proteins and analysis of a MAP kinase cascade in Arabidopsis. Biochem. Biophys. Res. Commun. 253, 532-543. doi: 10.1006/bbrc.1998.9796

Ichimura, K., Mizoguchi, T., Yoshida, R., Yuasa, T., and Shinozaki, K. (2000). Various abiotic stresses rapidly activate Arabidopsis MAP kinases ATMPK4 and ATMPK6. Plant J. 24, 655-665. doi: 10.1046/j.1365-313x.2000.00913.x 
Ichimura, K., Shinozaki, K., Tena, G., Sheen, J., Henry, Y., Champion, A., et al. (2002). Mapk G: Mitogen-activated protein kinase cascades in plants: a new nomenclature. Trends Plant Sci. 7, 301-308. doi: 10.1016/S13601385(02)02302-6

Jaillon, O., Aury, J. M., Noel, B., Policriti, A., Clepet, C., Casagrande, A., et al. (2007). The grapevine genome sequence suggests ancestral hexaploidization in major angiosperm phyla. Nature 449, 463-467. doi: 10.1038/nature06148

Jin, H., Axtell, M. J., Dahlbeck, D., Ekwenna, O., Zhang, S., Staskawicz, B., et al. (2002). NPK1, and MEKK1-like mitogen-activated protein kinase kinase kinase, regulates innate immunity and development in plants. Dev. Cell 3, 291-297. doi: 10.1016/S1534-5807(02)00205-8

Jonak, C., Ökrész, L., Bögre, L., and Hirt, H. (2002). Complexity, Cross Talk and Integration of Plant MAP Kinase Signalling. Curr. Opin. Plant Biol. 5, 415-424. doi: 10.1016/S1369-5266(02)00285-6

Jonak, C., Pay, A., Bogre, L., Hirt, H., and Heberle-Bors, E. (1993). The plant homologue of MAP kinase is expressed in a cell cycle-dependent and organspecific manner. Plant J. 3, 611-617. doi: 10.1046/j.1365-313X.1993.03040611.x

Jouannic, S., Hamal, A., Leprince, A. S., Tregear, J. W., Kreis, M., and Henry, Y. (1999). Characterisation of novel plant genes encoding MEKK/STE11 and RAF-related protein kinases. Gene 229, 171-181. doi: 10.1016/S03781119(99)00012-8

Katou, S., Yoshioka, H., Kawakita, K., Rowland, O., Jones, J. D., Mori, H., et al. (2005). Involvement of PPS3 phosphorylated by elicitor-responsive mitogenactivated protein kinases in the regulation of plant cell death. Plant Physiol. 139, 1914-1926. doi: 10.1104/pp.105.066795

Kieber, J. J., Rothenberg, M., Roman, G., Feldmann, K. A., and Ecker, J. R. (1993). CTR1, a negative regulator of the ethylene response pathway in Arabidopsis, encodes a member of the raf family of protein kinases. Cell 72, 427-441. doi: 10.1016/0092-8674(93)90119-B

Kiegerl, S., Cardinale, F., Siligan, C., Gross, A., Baudouin, E., Liwosz, A., et al. (2000). SIMKK, a mitogen-activated protein kinase (MAPK) kinase, is a specific activator of the salt stress-induced MAPK, SIMK. Plant Cell 12, 2247-2258. doi: 10.1105/tpc.12.11.2247

Kishi-Kaboshi, M., Okada, K., Kurimoto, L., Murakami, S., Umezawa, T., Shibuya, N., et al. (2010). A rice fungal MAMP-responsive MAPK cascade regulates metabolic flow to antimicrobial metabolite synthesis. Plant J. 63, 599-612. doi: 10.1111/j.1365-313X.2010.04264.x

Knetsch, M. L. W., Wang, M., Snaar-Jagalska, B. E., and Heimovaara-Dijkstra, S. (1996). Abscisic acid induces mitogen-activated protein kinase activation in barley aleuron protoplasts. Plant Cell 8, 1061-1067. doi: 10.1105/tpc.8. 6.1061

Kong, Q., Qu, N., Gao, M., Zhang, Z., Ding, X., Yang, F., et al. (2012). The MEKK1MKK1/MKK2-MPK4 kinase cascade negatively regulates immunity mediated by a mitogen-activated protein kinase kinase kinase in Arabidopsis. Plant Cell 24, 2225-2236. doi: 10.1105/tpc.112.097253

Kovtun, Y., Chiu, W. L., Tena, G., and Sheen, J. (2000). Functional analysis of oxidative stress-activated mitogen-activated protein kinase cascade in plants. Proc. Natl. Acad. Sci. U.S.A. 97, 2940-2945. doi: 10.1073/pnas.97.6.2940

Kumar, K., Rao, K. P., Biswas, D. K., and Sinha, A. K. (2011). Rice WNK1 is regulated by abiotic stress and involved in internal circadian rhythm. Plant Signal. Behav. 6, 316-320. doi: 10.4161/psb.6.3.13063

Kumar, K. R., and Kirti, P. B. (2010). A mitogen-activated protein kinase, AhMPK6 from peanut localizes to the nucleus and also induces defense responses upon transient expression in tobacco. Plant Physiol. Biochem. 48, 481-486. doi: 10.1016/j.plaphy.2010.03.010

Lee, J., Rudd, J. J., Macioszek, V. K., and Scheel, D. (2004). Dynamic changes in the localization of MAPK cascade components controlling pathogenesis-related (PR) gene expression during innate immunity in parsley. J. Biol. Chem. 279, 22440-22448. doi: 10.1074/jbc.M401099200

Leprince, A., Jouannic, S., Hamal, A., Kreis, M., and Henry, Y. (1999). Molecular characterisation of plant cDNAs BnMAP4K alpha 1 and BnMAP4K alpha 2 belonging to the GCK/SPS1 subfamily of MAP kinase kinase kinase kinase. Biochim. Biophys. Acta 1444, 1-13. doi: 10.1016/S0167-4781(98)00246-2

Liu, Q., and Xue, Q. (2007). Computational identification and phylogenetic analysis of the MAPK gene family in Oryza sativa. Plant Physiol. Biochem. 45, 6-14. doi: 10.1016/j.plaphy.2006.12.011

Liu, Y. (2012). Roles of mitogen-activated protein kinase cascades in ABA signaling. Plant Cell Rep. 31, 1-12. doi: 10.1007/s00299-011-1130-y
Liu, Y., Schiff, M., and Dinesh-Kumar, S. P. (2004). Involvement of MEK1 MAPKK, NTF6 MAPK, WRKY/MYB transcription factors, COI1 and CTR1 in N-mediated resistance to tobacco mosaic virus. Plant J. 38, 800-809. doi: 10.1111/j.1365-313X.2004.02085.x

Llompart, B., Castells, E., Río, A., Roca, R., Ferrando, A., Stiefel, V., et al. (2003). The direct activation of MIK, a germinal center kinase (GCK)-like kinase, by MARK, a maize atypical receptor kinase, suggests a new mechanism for signaling through kinase-dead receptors. J. Biol. Chem. 28, 48105-48111. doi: 10.1074/jbc.M307482200

Lukowitz, W., Roeder, A., Parmenter, D., and Somerville, C. (2004). A MAPKK kinase gene regulates extra-embryonic cell fate in Arabidopsis. Cell 116, 109-119. doi: 10.1016/S0092-8674(03)01067-5

Lynch, M., O'Hely, M., Walsh, B., and Force, A. (2001). The probability of preservation of a newly arisen gene duplicate. Genetics 159, 1789-1804.

Major, G., Daigle, C., Lafleur, E., Caron, S., and Matton, D. (2009). Characterization of ScMAP4K1, a MAP kinase kinase kinase kinase involved in ovule, seed and fruit development in Solanum chacoense Bitt. Curr. Topics Plant Biol. 10, 27-46.

Marchler-Bauer, A., Anderson, J. B., Chitsaz, F., Derbyshire, M. K., DeWeeseScott, C., Fong, J. H., et al. (2009). CDD: specific functional annotation with the Conserved Domain Database. Nucleic Acids Res. 37, D205-D210. doi: 10.1093/nar/gkn845

Matsuoka, D., Nanmori, T., Sato, K., Fukami, Y., Kikkawa, U., and Yasuda, T. (2002). Activation of AtMEK1, an Arabidopsis mitogen-activated protein kinase kinase, in vitro and in vivo: analysis of active mutants expressed in E. coli and generation of the active form in stress response in seedlings. Plant J. 29, 637-647. doi: 10.1046/j.0960-7412.2001.01246.x

Melech-Bonfil, S., and Sessa, G. (2010). Tomato MAPKKKepsilon is a positive regulator of cell-death signaling networks associated with plant immunity. Plant J. 64, 379-391. doi: 10.1111/j.1365-313X.2010.04333.x

Meng, X., Wang, H., He, Y., Liu, Y., Walker, J. C., Torii, K. U., et al. (2012). A MAPK cascade downstream of ERECTA receptor-like protein kinase regulates Arabidopsis inflorescence architecture by promoting localized cell proliferation. Plant Cell 24, 4948-4960. doi: 10.1105/tpc.112.104695

Mizoguchi, T., Ichimura, K., Irie, K., Morris, P., Giraudat, J., Matsumoto, K., et al. (1998). Identification of a possible MAP kinase cascade in Arabidopsis thaliana based on pairwise yeast two-hybrid analysis and functional complementation tests of yeast mutants. FEBS Lett. 437, 56-60. doi: 10.1016/S0014-5793(98)01197-1

Mizoguchi, T., Irie, K., Hirayama, T., Hayashida, N., Yamaguchi-Shinozaki, K., Matsumoto, K., et al. (1996). A gene encoding a mitogen-activated protein kinase kinase kinase is induced simultaneously with genes for a mitogenactivated protein kinase and an S6 ribosomal protein kinase by touch, cold, and water stress in Arabidopsis thaliana. Proc. Natl. Acad. Sci. U.S.A. 93, 765-769. doi: $10.1073 /$ pnas.93.2.765

Moreno-Hagelsieb, G., and Latimer, K. (2008). Choosing BLAST options for better detection of orthologs as reciprocal best hits. Bioinformatics 24, 319-324. doi: 10.1093/bioinformatics/btm585

Nadarajah, K., and Sidek, H. (2010). The green MAPKS. Asian J. Plant Sci. 9, 1-10. doi: 10.3923/ajps.2010.1.10

Nakagami, H., Kiegerl, S., and Hirt, H. (2004). OMTK1, a novel MAPKKK, channels oxidative stress signaling through direct MAPK interaction. J. Biol. Chem. 279, 26959-26966. doi: 10.1074/jbc.M312662200

Ning, J., Li, X., Hicks, L. M., and Xiong, L. (2010). A raf-like MAPKKK gene DSM1 mediates drought resistance through reactive oxygen species scavenging in rice. Plant Physiol. 152, 876-890. doi: 10.1104/pp.109.149856

Nishihama, R., Ishikawa, M., Araki, S., Soyano, T., Asada, T., and Machida, Y. (2001). The NPK1 mitogen-activated protein kinase kinase kinase is a regulator of cell-plate formation in plant cytokinesis. Genes Dev. 15, 352-363. doi: 10.1101/gad.863701

Nowak, M. A., Boerlijst, M. C., Cooke, J., and Smith, J. M. (1997). Evolution of genetic redundancy. Nature 388, 167-171. doi: 10.1038/40618

Oh, C.-S., Pedley, K. F., and Martin, G. B. (2010). Tomato 14-3-3 protein 7 positively regulates immunity-associated programmed cell death by enhancing protein abundance and signaling ability of MAPKKK $\alpha$. Plant Cell 22, 260-272. doi: $10.1105 /$ tpc. 109.070664

Ortiz-Masia, D., Perez-Amador, M. A., Carbonell, J., and Marcote, M. J. (2007). Diverse stress signals activate the $\mathrm{C} 1$ subgroup MAP kinases of Arabidopsis. FEBS Lett. 581, 1834-1840. doi: 10.1016/j.febslet.2007.03.075 
Pedley, K. F., and Martin, G. B. (2005). Role of mitogen-activated protein kinases in plant immunity. Curr. Opin. Plant Biol. 8, 541-547. doi: 10.1016/j.pbi.2005.07.006

Posas, F., and Saito, H. (1997). Osmotic activation of the HOG MAPK pathway via Ste11p MAPKKK: Scaffold role of Pbs2p MAPKK. Science 276, 1702-1705. doi: 10.1126/science.276.5319.1702

Qi, M., and Elion, E. A. (2005). MAP kinase pathways. J. Cell Sci. 118, 3569-3572. doi: $10.1242 /$ jcs. 02470

Qiu, J. L., Fiil, B. K., Petersen, K., Nielsen, H. B., Botanga, C. J., Thorgrimsen, S., et al. (2008). Arabidopsis MAP kinase 4 regulates gene expression through transcription factor release in the nucleus. Embo J. 27, 2214-2221. doi: 10.1038/emboj.2008.147

Rao, K. P., Richa, T., Kumar, K., Raghuram, B., and Sinha, A. K. (2010). In silico analysis reveals 75 members of mitogen-activated protein kinase kinase kinase gene family in rice. DNA Res. 17, 139-153. doi: 10.1093/dnares/ dsq011

Ren, D., Yang, H., and Zhang, S. (2002). Cell death mediated by MAPK is associated with hydrogen peroxide production in Arabidopsis. J. Biol. Chem. 277, 559-565. doi: 10.1074/jbc.M109495200

Rodriguez, M., Petersen, M., and Mundy, J. (2010). Mitogen-activated protein kinase signaling in plants. Annu. Rev. Plant Biol. 161, 621-649. doi: 10.1146/annurev-arplant-042809-112252

Rohila, J. S., and Yang, Y. (2007). Rice Mitogen-activated protein kinase gene family and its role in biotic and abiotic stress response. J. Integr Plant Biol. 49, 751-759. doi: 10.1111/j.1744-7909.2007.00501.x

Saitou, N., and Nei, M. (1987). The neighbor-joining method: a new method for reconstructing phylogenetic trees. Mol. Biol. Evol. 4, 406-425.

Sells, M. A., Knaus, U. G., Bagrodia, S., Ambrose, D. M., Bokoch, G. M., and Chernoff, J. (1997). Human p21-activated kinase (Pak1) regulates actin organization in mammalian cells. Curr. Biol. 7, 202-210. doi: 10.1016/S09609822(97)70091-5

Song, F., and Goodman, R. M. (2002). OsBIMK1, a rice MAP kinase gene involved in disease resistance responses. Planta 215, 997-1005. doi: 10.1007/s00425-0020794-5

Stulemeijer, I. J. E., Stratmann, J. W., and Joosten, M. H. A. J. (2007). Tomato mitogen-activated protein kinases LeMPK1, LeMPK2, and LeMPK3 are activated during the Cf-4/Avr4-Induced hypersensitive response and have distinct phosphorylation specificities. Plant Physiol. 144, 1481-1494. doi: 10.1104/pp.107.101063

Sugden, P. H., and Clerk, A. (1997). Regulation of the ERK subgroup of MAP kinase cascades through G protein-coupled receptors. Cell Signal. 9, 337-351. doi: 10.1016/S0898-6568(96)00191-X

Sun, Y., Wang, C., Yang, B., Wu, F., Hao, X., Liang, W., et al. (2014). Identification and functional analysis of mitogen-activated protein kinase kinase kinase (MAPKKK) genes in canola (Brassica napus L.). J. Exp. Bot. 65, 2171-2188. doi: 10.1093/jxb/eru092

Tamura, K., Peterson, D., Peterson, N., Stecher, G., Nei, M., and Kumar, S. (2011). MEGA5: Molecular Evolutionary Genetics Analysis using Maximum Likelihood, Evolutionary Distance, and Maximum Parsimony Methods. Mol. Biol. Evol. 28, 2731-2739. doi: 10.1093/molbev/msr121

Teige, M., Scheikl, E., Eulgem, T., Doczi, R., Ichimura, K., Shinozaki, K., et al. (2004). The MKK2 pathway mediates cold and salt stress signaling in Arabidopsis. Mol. Cell 15, 141-152. doi: 10.1016/j.molcel.2004. 06.023

Thompson, J. D., Higgins, D. G., and Gibson, T. J. (1994). CLUSTAL W: improving the sensitivity of progressive multiple sequence alignment through sequence weighting, position-specific gap penalties and weight matrix choice. Nucleic Acids Res. 22, 4673-4680. doi: 10.1093/nar/22.22.4673

Wang, G., Lovato, A., Liang, Y. H., Wang, M., Chen, F., Tornielli, G. B., et al. (2014a). Validation by isolation and expression analyses of MAPK gene family in grapevine (Vitis vinifera). Aust. J. Grape Wine Res. 20, 255-262. doi: 10.1111/ajgw.12081

Wang, G., Lovato, A., Polverari, A., Wang, M., Liang, Y. H., Ma, Y. C., et al. (2014b) Genome-wide identification and analysis of mitogen activated protein kinase kinase kinase gene family in grapevine (Vitis vinifera). BMC Plant Biol. 14:219 doi: 10.1186/s12870-014-0219-1

Wang, J., Pan, C., Wang, Y., Ye, L., Wu, J., Chen, L., et al. (2015). Genomewide identification of MAPK, MAPKK, and MAPKKK gene families and transcriptional profiling analysis during development and stress response in cucumber. BMC Genomics 16:386. doi: 10.1186/s12864-015-1621-2

Wang, L., Liu, Y., Cai, G., Jiang, S., Pan, J., and Li, D. (2014d). Ectopic expression of ZmSIMK1 leads to improved drought tolerance and activation of systematic acquired resistance in transgenic tobacco. J. Biotechnol. 20, 18-29. doi: 10.1016/j.jbiotec.2013.11.006

Wang, L., Su, H., Han, L., Wang, C., Sun, Y., and Liu, F. (2014c). Differential expression profiles of poplar MAP kinase kinases in response to abiotic stresses and plant hormones, and overexpression of PtMKK4 improves the drought tolerance of poplar. Gene. 15, 141-148. doi: 10.1016/j.gene.2014.04.058

Wang, X. J., Zhu, S. Y., Lu, Y. F., Zhao, R., Xin, Q., Wang, X. F., et al. (2010). Two coupled components of the mitogen-activated protein kinase cascade MdMPK1 and MdMKK1 from apple function in ABA signal transduction. Plant Cell Physiol. 51, 754-766. doi: 10.1093/pcp/pcq037

Wang, Y., Liu, K., Liao, H., Zhuang, C., Ma, H., and Yan, X. (2008). The plant WNK gene family and regulation of flowering time in Arabidopsis. Plant Biol. 10, 548-562. doi: 10.1111/j.1438-8677.2008.00072.x

Wilson, C., Voronin, V., Touraev, A., Vicente, O., and Heberle-Bors, E. (1997). A developmentally regulated MAP kinase activated by hydration in tobacco pollen. Plant Cell 9, 2093-2100. doi: 10.1105/tpc.9.11.2093

Yang, K.-Y., Liu, Y., and Zhang, S. (2001). Activation of a mitogen-activated protein kinase pathway is involved in disease resistance in tobacco. Proc. Natl. Acad. Sci. U.S.A. 98, 741-746. doi: 10.1073/pnas.98.2.741

Yuasa, T., Ichimura, K., Mizoguchi, T., and Shinozaki, K. (2001). Oxidative stress activates ATMPK6, an Arabidopsis homologue of MAP kinase. Plant Cell Physiol. 42, 1012-1016. doi: 10.1093/pcp/pce123

Zaïdi, I., Ebel, C., Touzri, M., Herzog, E., Evrard, J.-L., Schmit, A., et al. (2010). TMKP1 is a novel wheat stress responsive MAP kinase phosphatase localized in the nucleus. Plant Mol. Biol. 73, 325-338. doi: 10.1007/s11103-010-9617-4

Zhang, S., and Klessig, D. F. (1997). Salicylic acid activates a 48-kD MAP kinase in tobacco. Plant Cell 9, 809-824. doi: 10.1105/tpc.9.5.809

Zhang, S., and Klessig, D. F. (2001). MAPK cascades in plant defense signaling. Trends Plant Sci. 6, 520-527. doi: 10.1016/S1360-1385(01)02103-3

Conflict of Interest Statement: The authors declare that the research was conducted in the absence of any commercial or financial relationships that could be construed as a potential conflict of interest.

Copyright () 2015 Çakır and Killçkaya. This is an open-access article distributed under the terms of the Creative Commons Attribution License (CC BY). The use, distribution or reproduction in other forums is permitted, provided the original author(s) or licensor are credited and that the original publication in this journal is cited, in accordance with accepted academic practice. No use, distribution or reproduction is permitted which does not comply with these terms. 